\title{
Defluoridation of Aqueous Solution Using Thermally Activated Biosorbents Prepared from Adansonia digitata Fruit Pericarp
}

\author{
David Mihayo, Maheswara Rao Vegi $(D$, and Said Ali Hamad Vuai \\ The Department of Chemistry, College of Natural and Mathematical Sciences, The University of Dodoma, Dodoma, Tanzania \\ P.O. Box 259 \\ Correspondence should be addressed to Maheswara Rao Vegi; vegi.rao@udom.ac.tz
}

Received 20 February 2021; Revised 26 April 2021; Accepted 11 May 2021; Published 27 May 2021

Academic Editor: George Kyzas

Copyright (C) 2021 David Mihayo et al. This is an open access article distributed under the Creative Commons Attribution License, which permits unrestricted use, distribution, and reproduction in any medium, provided the original work is properly cited.

\begin{abstract}
The presence of fluoride ions in water poses a significant danger to human health. In Tanzania, where the Rift Valley passes, some people are impaired due to elevated levels of fluoride in water. The purpose of this study was to prepare thermally activated Adansonia digitata fruit pericarp biosorbents at $450,500,550$, and $600^{\circ} \mathrm{C}$ for defluoridation. Using the Brunauer-Emmett-Teller analyzer, the surface area and pore diameter were measured. The scanning electron microscope and Fourier transform infrared spectrometry were used to determine morphological features and functional groups of biosorbents. To analyze the effect of $\mathrm{pH}$, adsorbent dose, contact time, and initial concentration, the response surface methodology was applied. Adsorption isotherms, kinetics, and regeneration studies were also conducted. There were considerably wide surface areas of 385.44, 399.27, 445.71, and $447.70 \mathrm{~m}^{2} / \mathrm{g}$ and pore diameters of $0.3055,3.0341,3.0375$, and $3.0471 \mathrm{~nm}$ for biosorbents activated at 450, 500, 550, and $600^{\circ} \mathrm{C}$, respectively. FT-IR spectra indicated the oxidation of alcoholic $-\mathrm{OH}$ to carboxylic $-\mathrm{OH}$ during the activation process, which is proved by the shifting of the peak at $3500-3000 \mathrm{~cm}^{-1}$ from raw biosorbent to a very broad and strong band at 3500 $2000 \mathrm{~cm}^{-1}$ from the activated biosorbent. The maximum removal efficiencies of biosorbents activated at $450,500,550$, and $600^{\circ} \mathrm{C}$ were 95.55, 96.50, 97.65, and 98.36\%, respectively, for all biosorbents at a $\mathrm{pH}$ of 2 , an initial concentration of $27.50 \mathrm{ppm}$, a contact period of 75.00 minutes, and an adsorbent dose of $5.50 \mathrm{~g}$, which indicates that the adsorbents were successful for fluoride removal. The isotherms and kinetics indicated that the adsorption fitted well with Freundlich $\left(R^{2}=0.95661-0.98445\right)$ and pseudo-second-order $\left(R^{2}=0.94230-0.99634\right)$ kinetic adsorption models, respectively. The results showed that the removal of fluoride by biosorbents prepared is effective and could be used for defluoridation of drinking water.
\end{abstract}

\section{Introduction}

Water is one of life's fundamental needs on earth. Natural sources or anthropogenic activities such as mining, farming, and construction may contaminate it. Fluoride is one of the noxious and detrimental pollutants. The presence of highlevel fluoride ions in water bodies, including several regions of Africa, Asia, and China, is a global concern. More than 30 million people are seriously affected by fluorosis, and another 100 million are exposed to it in China, according to recent reports [1].

Fluoride is a naturally occurring product present in rocks, geochemical deposits, and natural water systems and enters the food chain via drinking water or plants and cereals [2]. It occurs in conjunction with other ele- ments in various chemical forms. It is widely distributed, both in inanimate and living things, in nature [3]. While fluoride is an important component, it can be either beneficial or detrimental to human health depending on the level of fluoride in drinking water [4]. The tolerance limit for the fluoride content of drinking water is $1.5 \mathrm{mg} / \mathrm{L}$, according to the World Health Organization [5]. Dental, skeletal, and nonskeletal fluorosis occurs when the concentration of fluoride in drinking water is above $1.5 \mathrm{mg} / \mathrm{L}$ due to its intense attraction to positively charged calcium ions in teeth and bones [6]. Tanzania is one of the countries in the world where the harmful effects of high levels of fluoride in drinking water are toxic to a large number of its population. Groundwater is used by people in many regions of Tanzania as their primary source of potable 
water in rural areas. Groundwater contains high fluoride ion concentrations in some areas of Tanzania where the Great Rift Valley passes, as recommended by WHO [5]. Dental, skeletal, or debilitating fluorosis may be caused by fluoride concentrations varying from 1.5 to $10 \mathrm{mg} / \mathrm{L}$ [7]. People from rural areas, especially in Arusha, Kilimanjaro, Singida, and Shinyanga, are vulnerable to fluorosis because fluoride ion concentrations greater than $1.5 \mathrm{mg} / \mathrm{L}$ are found in groundwater in these regions.

To tackle the issue of fluoride in water, many remediation strategies have been identified. Precipitation, ion exchange, reverse osmosis, electrodialysis, distillation, chemical reduction, nanofiltration, and electrocoagulation are all used in these techniques. These approaches face challenges in terms of planning and operating costs and requirements for qualified engineers and manpower, despite the high remediation performance. A certain degree of fluoride remediation capability has been shown by these methods, but some of them can only be used in a small $\mathrm{pH}$ range (5-6), and some of them are too costly to consider for full-scale water treatment [8]. The adsorption process has therefore been reported to be effective for removing contaminants at the level of households and small community schemes [9]. It has many advantages, such as low adsorbent preparation costs, easy accessibility, a broad variety of industrial use, biological and domestic waste, low operating costs, ability to extract pollutant ions across a wide $\mathrm{pH}$ range and to a much lower level, and ability to remove complex types of contaminants that are not normally possible by other methods. It is also environmentally friendly, considering the use of biomaterials [10].

The study of fluoride removal using natural, synthetic, and biomass materials such as activated alumina, fly ash, alum sludge, chitosan beads, red mud, zeolite, calcite, hydrated cement, attapulgite, and acid-treated spent bleaching earth has received considerable attention in recent years [11]. It is therefore paramount to plan and analyze cost-effective, environmentally safe, and locally available defluoridation products that can be accessible by all individuals and capable of reducing fluoride ion concentrations to appropriate levels. Thermally activated biosorbents prepared from Adansonia digitata fruit pericarp (ADFP) have shown the capability to attenuate fluoride ion concentrations into acceptable levels suggested by WHO and UNICEF [12]. Therefore, these materials are suitable for removing fluoride ions from water at an affordable cost. But there are no studies on the activated biosorbents prepared from ADFP for defluoridation. Therefore, the present study focused on the development and characterization of biosorbents that will be robust, porous, and able to effectively remove fluoride in subsequent operations and must be environment-friendly. In this study, thermally activated biosorbents were prepared from Adansonia digitata fruit pericarp (TAADFP) to remove fluoride from an aqueous solution. Moreover, TAADFPs developed in the present study were prepared differently by soaking in distilled water overnight and then dried to increase the number of pores, stability of the adsorbents, and cleanliness of the filtrate.

\section{Materials and Methods}

2.1. Materials. For the preparation of thermally activated biosorbents, the precursor, Adansonia digitata fruit pericarps, was collected from Dodoma, Tanzania. This study used sulphuric acid (AR, 98 percent assay, RANKEM India), glacial acetic acid (AR, 99.5 percent assay, RANKEM India), iodine, potassium iodide, sodium fluoride, hydrochloric acid, and sodium hydroxide.

2.2. Preparation of Thermally Activated Biosorbents. In order to eliminate dust and other unwanted materials, small pieces of pericarp were washed and then treated with hot distilled water to remove color and dried at $100^{\circ} \mathrm{C}$ using an oven. To extract moisture and other volatile impurities, dried materials were kept in the furnace at $150^{\circ} \mathrm{C}$ for 24 hours. After that, $100 \mathrm{~g}$ of the materials was treated with $50 \mathrm{~mL}$ of concentrated $\mathrm{H}_{2} \mathrm{SO}_{4}$ and was carbonized at various temperatures of $450,500,550$, and $600^{\circ} \mathrm{C}$ using an electric furnace [13]. Concentrated $\mathrm{H}_{2} \mathrm{SO}_{4}$ has been used because it serves as a dehydrating reagent to lower the temperature of carbonization and limit tar formation, as well as to facilitate carbon charring. The materials were heated to the final temperature at a heating rate of $10^{\circ} \mathrm{C} / \mathrm{min}$ with a nitrogen flow rate of $120 \mathrm{~cm}^{3} / \mathrm{min}$. For each final carbonation temperature, these materials were kept inside the furnace for one hour. They were then fully cooled under a steady nitrogen gas flow. To extract residual organic and mineral matter, the adsorbents were dried and then washed several times with $0.5 \mathrm{M} \mathrm{HCl}$ followed by warm distilled water. They were then washed with cold water until the solution became neutral. Then, overnight, they were immersed in cold water. Later, they were dried in an oven at $150^{\circ} \mathrm{C}$ for 24 hours and packed after cooling in sealed airtight containers for preservation so that they did not react to the neighboring climate.

\subsection{Characterization of Biosorbents}

2.3.1. Moisture Content. The initial weight of the sample $(5 \mathrm{~g})$ was measured and taken in a petri dish. It was then heated in an oven at a temperature of $105^{\circ} \mathrm{C}$ for 2 hours. After heating, it was cooled in a desiccator. The final weight of the dried sample has now been measured. Using equation (1) stipulated by Verla et al. [13], the percentage of moisture content was determined:

$$
\% \text { Moisture content }=\frac{\text { Weight of moisture }}{\text { Weight of original sample }} \times 100 \text {. }
$$

2.3.2. Volatile Matter Content. The sample's initial weight (5g) was weighed and taken in a crucible closed with a lid and combusted in a muffle furnace for 7 minutes at a temperature of $925^{\circ} \mathrm{C}$. The crucible was then cooled in a desiccator, and the final weight of the sample being combusted was weighed. By using equation (2) given by Rangari and Chavan [14], the percentage of volatile matter content was 
determined:

$\%$ Volatile matter content $=\frac{\text { Weight of volatile matter }}{\text { Weight of original sample }} \times 100$.

2.3.3. Pore Volume and Porosity. The $1 \mathrm{~g}$ biosorbent sample was transferred into a $10 \mathrm{~mL}$ measuring cylinder, and the particle volume was recorded. This sample was put in a $20 \mathrm{~mL}$ distilled water beaker and boiled for 5 minutes to replace the air in the sample. The content was superficially dried and weighed. The pore volume for the sample was provided by the increase in the weight of the sample divided by the water density. By dividing the pore volume of the particle by the total volume of the particle [15], the porosity was determined.

2.3.4. BET Analysis. The surface area and pore size of the biosorbents were determined using an automated gas sorption analyzer, Quanta Chrome Nova Win version 11.03, by measuring nitrogen adsorption-desorption at $77.35 \mathrm{~K}$. The area of the surface was measured according to the method of Brunauer-Emmet-Teller (BET).

2.3.5. Iodine Number. Information about the degree of microporosity is given by the iodine number. It is a measure of the capacity of activated carbon to adsorb compounds of low molecular weight. A typical solution of iodine was prepared and stored in a light-resistant container by dissolving $2.7 \mathrm{~g}$ of $\mathrm{I} 2$ and $4.1 \mathrm{~g}$ of $\mathrm{KI}$ in 1 liter of deionized water. The standard solution of iodine was treated with the biosorbents under analysis, and the number of iodines was calculated according to the Das et al. [16] and Mopoung et al. [17] protocol.

2.3.6. Methylene Blue Number. The methylene blue number is described as the maximum quantity of dye adsorbed by $1.0 \mathrm{~g}$ of adsorbent. It is intended for the determination of the degree of adsorbent mesoporosity. The degree of mesoporosity means that medium-sized molecules such as methylene blue dye may be adsorbed by the adsorbent. At room temperature, $10.0 \mathrm{~g}$ of activated carbon was mixed with $10.0 \mathrm{~mL}$ of methylene blue solution at varying concentrations $(10,25,50,100,250,500$, and $1000 \mathrm{mg} / \mathrm{L})$ for 24 hours. Using a UV/visible spectrophotometer, the remaining concentration of methylene blue was analyzed. Using equation (3), methylene blue adsorbed from each solution was determined, as explained by Fil et al. [18] and Nunes and Guerreiro [19]:

$$
q_{\mathrm{eq}}(\mathrm{mg} / \mathrm{g})=\frac{C_{0}-C_{e}}{M} \times V .
$$

2.3.7. Morphology. The morphology, pore size, area, and volume of TAADFPs were visualized using a scanning electron microscope (SEM) (SSX-550, Shimadzu, Japan). By scanning through an electron beam, SEM enables the visualization of the surface features of a solid sample by images [20]. It was coated with gold or silver to make it conductive for $30 \mathrm{sec}-$ onds at a current of $50 \mathrm{~mA}$ and an accelerating voltage of
$15 \mathrm{kV}$ prior to the SEM scanning of the sample. For the study, it was then put into an SEM holder. In the range of 20x to 5000x using JSM 6380A, SEM photographs were taken at various magnifications.

2.3.8. Ion Exchange Capacity. To assess the cation and anion exchange power of sorbents, Boehm titration was used [21]. In an Erlenmeyer flask, a known amount of adsorbent $(1 \mathrm{~g})$ was put. A volume of $20 \mathrm{~mL}$ of $0.1 \mathrm{M} \mathrm{NaOH}$ solution was applied. The suspension was shaken at a rate of $200 \mathrm{rpm}$ for 24 hours at room temperature $\left(27 \pm 2^{\circ} \mathrm{C}\right)$ to reach equilibrium. The residual $\mathrm{NaOH}$ concentration was calculated after filtration by titration with $0.1 \mathrm{M} \mathrm{HCl}$ using phenolphthalein as an indicator. The quantity of $\mathrm{NaOH}$ adsorbed by the biosorbent was calculated.

2.3.9. $\mathrm{pH}$ at the Point of Zero Charge. The point of zero charge, $\mathrm{pH}_{\mathrm{pzc}}$, quantifies the acidic or basic character of the carbon. The carbon surface is positively charged at $\mathrm{pH}<\mathrm{p}$ $\mathrm{H}_{\mathrm{pzc}}$ and negatively charged at $\mathrm{pH}>\mathrm{pH}_{\mathrm{pzc}}$. The $\mathrm{pH}$ at the point of zero charge $\left(\mathrm{pH}_{\mathrm{pzc}}\right)$ for each adsorbent was determined by using the solid addition method. $1.0 \mathrm{~g}$ of activated carbon was introduced into six $100 \mathrm{~mL}$ Erlenmeyer flasks containing $100 \mathrm{~mL}$ of 0.1 potassium nitrate solution, and the flasks were sealed. Initial $\mathrm{pH}$ values of the six solutions were adjusted to $2,4,6,8,10$, and 12 by adding a few drops of either $0.1 \mathrm{M} \mathrm{HCl}$ or $\mathrm{NaOH}$ solutions. The $\mathrm{pH}$ of each solution was measured by using a $\mathrm{pH}$ meter (B729 Eutect-Singapore). The solution mixtures were allowed to equilibrate in an isothermal shaker $\left(25 \pm 1^{\circ} \mathrm{C}\right)$ for 24 hours at a rate of $200 \mathrm{rpm}$. Then, the suspension in each sample was filtered, and the final $\mathrm{pH}$ was measured. The value of $\mathrm{pH}_{\mathrm{pzc}}$ was determined from the plot of $\Delta \mathrm{pH}$ versus $\mathrm{pH}$ [22]. The $\mathrm{pH}$ at which the $x$-axis is crossed by the curve was taken as $\mathrm{pH}_{\mathrm{pzc}}$.

2.3.10. Functional Group Analysis. The Fourier transform infrared (FT-IR) spectrophotometer was used, as defined by Adewuyi and Pereira [23], to identify the functional groups present and bonding patterns of the thermally activated biosorbent. To obtain spectra and record characteristic peaks in wavenumbers ranging from 350 to $4000 \mathrm{~cm}^{-1}$ and 100 scans per sample at a resolution of $4 \mathrm{~cm}^{-1}$, a Perkin Elmer spectrum 100 FT-IR spectrophotometer was used (United Kingdom). By grinding with $\mathrm{KCl}$, the samples were prepared (carbon: $\mathrm{KCl}$ mass ratio of $1: 100)$.

2.4. Calibration of the Instrument. The fluoride ion-selective electrode system (Hach, USA) was calibrated using five standards of fluoride solutions diluted from a stock solution in the range of 1 to $50 \mathrm{mg} / \mathrm{L}$ to ensure good performance of the instrument and create a linear equation for the determination of unknown concentrations. The logarithm graph of fluoride ion concentrations $(\mathrm{mg} / \mathrm{L})$ against potential $(\mathrm{mV})$ showed a straight line with slopes ranging from -54.94 to $-55.73 \mathrm{mV}$, within the theoretical range of -50 to $-60 \mathrm{mV}$ at $25^{\circ} \mathrm{C}$ [3]. The linearity of the graphs was shown by the correlation coefficient $(r)$ of Pearson ranging between -0.99963 and -0.99875 and $R^{2}$ ranging between -0.99963 and -0.99875 . 
2.5. Optimization of Parameters. Response surface methodology (RSM), which is an effective statistical technique for multiparameter optimization, was used in this study to obtain a series of experiments designed to obtain an optimal response $[24,25] . \mathrm{pH}$, contact time, initial concentration, and adsorbent dose are included in the parameters. With the assistance of the Design-Expert (version dx 7) statistical tool, the experimental design was carried out. To evaluate the effect of the operating parameters on adsorption performance, the Central Composite Design (CCD) was used. To test multiple parameters and their interactions, CCD reduces the number of experimental trials needed [25]. It is useful because it generates tremendous data by carrying out a limited number of experiments. It also offers the possibility to analyze the effects of a single variable on the response and their mixture of interactions. For all the adsorbents, the results of CCD were used to study the mutual effects of the parameters and optimum parameters according to RSM. The ranges analyzed were 210 , 30-120 min, 5-50 mg/L, and 1-10 g, respectively, for $\mathrm{pH}$, initial concentration, contact time, and adsorbent dose. To obtain the number of experiments and the set of parameters under consideration, these levels were introduced into the Design-Expert statistical program.

According to the experimental conditions set by the program, batch experiments were carried out where $100 \mathrm{~mL}$ of simulated water was mixed with each adsorbent and agitated at room temperature at $200 \mathrm{rpm}$ on a mechanical shaker. Then, a Whatman No. 42 filter paper was used to filter the mixture. The fluoride concentrations were measured using the fluoride ion-selective electrode potentiometric method. The concentration of fluoride ion adsorbed on the adsorbent was measured as the difference between the initial solution concentration and the postsorption solution concentration. The adsorption efficiency (\%) and the adsorption capacity (mg adsorbate adsorbed/g of adsorbent) for each experiment were determined using equations (4) and (5), respectively [20]:

$$
\begin{aligned}
& \text { Adsorption efficiency }=\frac{\left[C_{0}-C_{t}\right]}{\left[C_{0}\right]} \times 100, \\
& \text { Adsorption capacity }=\frac{\left[C_{0}-C_{t}\right]}{m} \times V .
\end{aligned}
$$

2.6. Adsorption Isotherms. The isotherms of Langmuir and Freundlich adsorption were studied at a $\mathrm{pH}$ of $6.90 \pm 0.10$ by varying the adsorbent dosage from 2 to $10 \mathrm{~g}$ and mixing for 24 hours with $50 \mathrm{~mL}$ fluoride solution $(50 \mathrm{mg} / \mathrm{L})$ to allow equilibrium at room temperature $\left(27 \pm 2^{\circ} \mathrm{C}\right)$. From the experimental results, all the values needed to plot the isotherms were determined as shown elsewhere [26].

2.7. Kinetic Studies. Kinetic studies were carried out at different time intervals of 10-50 minutes by adjusting the $\mathrm{pH}$ at $6.90 \pm 0.10$ and room temperature $\left(27 \pm 2^{\circ} \mathrm{C}\right)$. All of these tests were performed by taking $50 \mathrm{~mL}$ of fluoride solution with an initial $50 \mathrm{mg} / \mathrm{L}$ concentration. As explained by Fan et al., the findings obtained from kinetic experiments were analyzed using pseudo-first- and second-order models [27].
2.8. Regeneration and Reusability. To regenerate the adsorbent, desorption experiments were carried out using $\mathrm{NaCl}$ $(0.1 \mathrm{M})$ in the desorbing media-distilled water. After the adsorption process, the adsorbent was separated and washed several times with deionized water to remove any unadsorbed pollutant ions, and then, desorption studies were performed. The pollutant-loaded biosorbents were transferred and agitated with $1 \mathrm{~L}$ of eluant solution, $\mathrm{NaCl}$ in the water shaker bath for 1 hour. It was again filtered, and then, the concentrations of pollutant ions desorbed in the filtrate were determined. The eluted biosorbents were washed several times with distilled water to remove excess salt and acid. The biosorbents regenerated were then used in the next biosorption process. Three cycles of biosorption-desorption were conducted, and the experiments were operated under the same conditions during the entire process. For each cycle, the adsorption efficiency of the regenerated adsorbent was determined.

\section{Results and Discussion}

\subsection{Characterization of Adsorbents}

3.1.1. Moisture Content. The moisture contents of TAADFPs activated at $450,500,550$, and $600^{\circ} \mathrm{C}$ were found as $3.5,3.3$, 3.1 , and $2.8 \%$, respectively. It decreased as the activation temperature increased. This is because the dehydration rate of the activated carbon increased with an increase in activation temperature. Any porous material tends to absorb moisture. The moisture content of all the adsorbents was near normal and comparable with the values reported elsewhere [14]. An adsorbent with a lower amount of moisture is better than that higher. This is for three reasons. The first one is a part of external moisture which is combined with the adsorbent surface by wetting action and which occupies a certain amount of adsorptive space. Secondly, there will be competition between the moisture and the fluoride toward active sites of the adsorbent. Thirdly, the moisture will block the fluoride ions from passing into the pore channels [28]. Therefore, TAADFPs have better adsorption characteristics concerning the moisture content. According to Gumus and Okpeku [15], the recommendable moisture content ranged between 3 and $6 \%$. The moisture contents portrayed by the TAADPs were within the recommendable range.

3.1.2. Volatile Matter Content. Volatile matter is due to the presence of organic compounds present in the raw material. This gives information on the suitability of the precursor for carbon preparation. The volatile matter content of TAADFPs activated at $450,500,550$, and $600^{\circ} \mathrm{C}$ was found as $11.2,10.3,9.2$, and $8.5 \%$, respectively. The volatile matter content of activated carbon decreased with an increase in activation temperature. When activation temperature was increasing, devolatilization was increased, and hence, the prepared activated carbon had a low volatile matter content. This implies that most of the volatile organic matter escaped during the preparation of the materials, and it is an indication that the activated carbons were well devolatilized. Research by Veena Devi et al. [29] reported volatile matter 
content ranging from $20.67 \%$ to $22.67 \%$, which means that better adsorbents are TAADFPs. This suggests that Adansonia digitata fruit pericarp is suitable for preparing biosorbents.

3.1.3. Pore Volume and Porosity. The pore volumes of TAADFPs activated at $450,500,550$, and $600^{\circ} \mathrm{C}$ were found as $3.0,3.8,4.0$, and $4.8 \mathrm{~cm}^{3} / \mathrm{g}$, respectively. The pore volumes increase with an increase in activation temperature. This is due to the increase in the rate of evaporation and devolatilization of small molecules leaving behind pores. The recommended pore volume ranged from 2 to $5 \mathrm{~cm}^{3} / \mathrm{g}$ [30]. The values obtained in this study are within the recommendable range for the biosorbent prepared from agricultural wastes. The pore volumes are between medium (mesoporous) and small (microporous), suggesting that both small and large molecules can be removed from aqueous solutions by TAADFPs.

Porosity is the ratio of a material's pore volume to the bulk volume (adsorbent). The number of pores present in the adsorbents is defined by porosity. Therefore, porosity increases the adsorption power of the adsorbent [13]. The porosity values of TAADFPs activated at $450,500,550$, and $600^{\circ} \mathrm{C}$ were found as $0.35,0.38,0.50$, and 0.56 , respectively. Most of these values are different for activated carbons prepared from snail shell waste from the recorded values $(0.28$ and 0.38) by Gumus and Okpeku [15]. Similar trends of porosity as that of pore volume were exhibited by the biosorbent for the same reason.

3.1.4. BET Analysis. The surface areas of TAADFPs activated at $450,500,550$, and $600^{\circ} \mathrm{C}$ were $385.44,399.27,445.71$, and $447.70 \mathrm{~m}^{2} / \mathrm{g}$, respectively. All the adsorbents had a considerably large surface area and thus had a high adsorption potential on the surface. Adsorbents with a very high surface area of $200-300 \mathrm{~m}^{2} / \mathrm{g}$ have a significant number of active sites including functional groups to promote the adsorption of different anions and cations from water [8].

The pore diameters of TAADFPs activated at 450,500 , 550 , and $600^{\circ} \mathrm{C}$ were $0.3055,3.0341,3.0375$, and $3.0471 \mathrm{~nm}$, respectively. A pore diameter of less than $2 \mathrm{~nm}$ is known to have microporosity, and greater than $2 \mathrm{~nm}$ is mesoporous, according to the IUPAC classification [30]. Both surface area and pore diameter increased with an increase in activation temperature with proper development of the porous structure. This is an indication that there was the formation of a well-developed porous structure and an abundance of surface functional groups on the adsorbent's surface; adsorbates could be removed through interaction with these functional groups. In the present study, the pore diameter obtained revealed that TAADFP activated at $450^{\circ} \mathrm{C}$ was microporous and that the rest was mesoporous $[11,31]$.

3.1.5. Iodine Number $(\mathrm{mg} / \mathrm{g})$. It is a measure of the adsorbent's ability to adsorb low-molecular-weight compounds as the iodine molecule is relatively small and so provides a measure of the surface area available to small adsorbates such as fluoride. The iodine number gives information about the degree of microporosity. Generally, the higher the iodine number, the greater the sorption capacity. The iodine numbers of TAADFPs activated at $450,500,550$, and $600^{\circ} \mathrm{C}$ were found as $515,590,620$, and $650 \mathrm{mg} / \mathrm{g}$, respectively. It increased from low activation temperature to high activation temperature. This is due to an increase in dehydration and devolatilization rate as the result of an increase in processing temperature. The values obtained in this study are within the reported values $\left(440-700 \mathrm{~m}^{2} / \mathrm{g}\right)$ by Veena Devi et al. [29] and Das et al. [16]. In this study, the iodine numbers obtained revealed that the adsorbents have a greater sorption capacity.

3.1.6. Methylene Blue Number ( $m g / g)$. Large methylene blue number values suggest that mesopores are possessed by the materials. The degree of mesoporosity is an indicator that medium-sized molecules such as methylene blue dye in mesopores can be adsorbed by the adsorbent [17]. The methylene blue numbers of TAADFPs activated at $450,500,550$, and $600^{\circ} \mathrm{C}$ were found as $196,205,228$, and $258 \mathrm{mg} / \mathrm{g}$, respectively, indicating the presence of mesopores. The values of the methylene blue number increased with an increase in activation temperature. This is due to the burn-off of volatile materials. The values obtained for TAADFPs activated above $450^{\circ} \mathrm{C}$ in this study were higher than those obtained for chemically activated plants $(130 \mathrm{mg} / \mathrm{g})$ and chemically activated carbon $(200 \mathrm{mg} / \mathrm{g})$ by Bestani et al. [32].

3.1.7. Morphology. The morphology of TAADFPs activated at $450,500,550$, and $600^{\circ} \mathrm{C}$ can be seen in micrographs obtained from a scanning electron microscope (SEM) (Figure 1). These adsorbents are found to have an uneven rough surface, surface channels on the surface, and a welldeveloped porous surface with randomly distributed pores of various sizes. So, the pore arrangement of these adsorbents is heterogeneous. They have a large number of mesopores and a small number of micro- and macropores, allowing them to adsorb contaminants of various sizes. The generation and widening of pores increased from 450 to $600^{\circ} \mathrm{C}$ as the activation temperature increased. The results of the iodine number, methylene blue number, and BET surface area that showed high surface area are consistent with these SEM results. Fluoride ion adsorption is due to the presence of pores and channels.

3.1.8. Ion Exchange Capacity. The reduction of $\mathrm{OH}^{-}$ions in the solution was very significant in this study. The anion exchange capacity of TAADFPs activated at 450, 500, 550, and $600^{\circ} \mathrm{C}$ was $91,94,96$, and $99 \%$, respectively. All the adsorbents can efficiently adsorb anions. The reduction of $\mathrm{OH}^{-}$ions in the solution was increased as the processing temperature increased. This is because exposure of functional groups and the development of pores increased as temperature increased due to complete combustion, dehydration, and devolatilization. Also, adsorption of $\mathrm{OH}^{-}$was mainly attributed to ion exchange and electrostatic attraction due to the presence of exchangeable chloride ions of adsorbent and positively charged adsorbent surface, respectively [33].

3.1.9. $\mathrm{pH}$ at Point of Zero Charge. $\mathrm{pH}$ at point of zero charge was studied in the $\mathrm{pH}$ range of 2 to 12 with an interval of 2 . The $\mathrm{pH}$ at which the line intersects the axis corresponding 


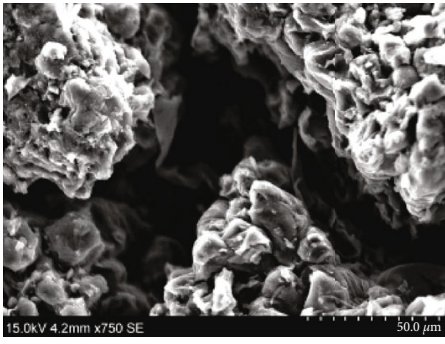

(a)

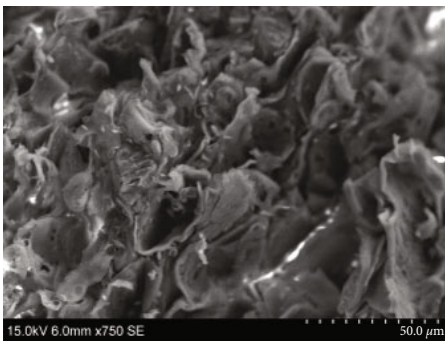

(c)

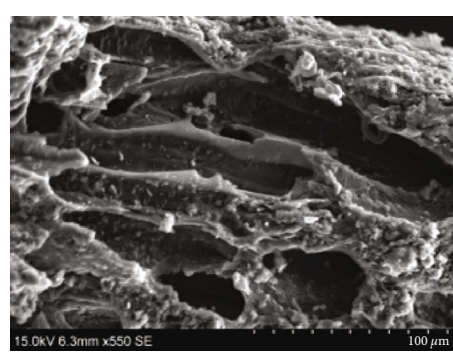

(b)

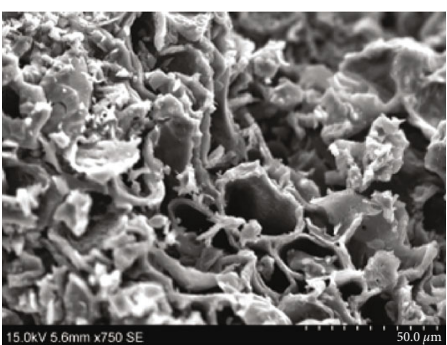

(d)

Figure 1: Scanning electron micrographs of TAADFPs activated at (a) $450^{\circ} \mathrm{C}$, (b) $500^{\circ} \mathrm{C}$, (c) $550^{\circ} \mathrm{C}$, and (d) $600^{\circ} \mathrm{C}$.

to $\Delta \mathrm{pH}=0$ is the $\mathrm{pH}_{\mathrm{pzc}}$. Figure 2 shows that the adsorbent TAADFPs activated at $450,500,550$, and $600^{\circ} \mathrm{C}$ were neutral at $\mathrm{pH}=6.0,8.0,6.5$, and 9.0, respectively, where $\Delta \mathrm{pH}=0$ and is called as $\mathrm{pH}_{\mathrm{pzc}}$. The $\mathrm{pH}$ values below $\mathrm{pH}_{\mathrm{pzc}}$ indicated that there were prominences of net positive surface charges of adsorbent and they could adsorb anions [20]. It was noticed that the adsorbent showed more adsorption for fluoride ions at less $\mathrm{pH}$ than $\mathrm{pH}_{\mathrm{pzc}}$ and more adsorption of cations at more $\mathrm{pH}$ than $\mathrm{pH}_{\mathrm{pzc}}$. The net charge of the adsorbent's surface was zero at $\mathrm{pH}_{\mathrm{pzc}}$, and it is positively charged at $\mathrm{pH}$ less than that. It can be stated that the adsorption of anions on the surface is favored when the surface is positive. Therefore, it is expected that TAADFPs activated at 450,500,550, and $600^{\circ} \mathrm{C}$ will remove $\mathrm{F}^{-}$from aqueous solution to a greater extent below the $\mathrm{pH}$ of $6.0,8.0,6.5$, and 9.0, respectively.

3.1.10. Analysis of Functional Groups. The functional groups and the effect of the activation temperature on the surface functional groups of TAADFPs were analyzed using the FT-IR spectrophotometer. The FT-IR spectral analysis showed that many functional groups for the adsorption process are available on the surface of adsorbents.

All TAADFP spectra showed similar peaks (Figure 3). The peak at $3500-3000 \mathrm{~cm}^{-1}$ from raw adsorbent shifted to $3500-2000 \mathrm{~cm}^{-1}$ as a very broad and strong band indicating the oxidation of alcoholic $-\mathrm{OH}$ to carboxylic $-\mathrm{OH}$ during the activation process. This broad peak enveloped the peaks of $-\mathrm{C}-\mathrm{H}$ stretching at $2900 \mathrm{~cm}^{-1}$. There is no effect of activation temperature on the peaks at the carbonyl region $\left(1700-1800 \mathrm{~cm}^{-1}\right)$. There are two peaks in the carbonyl range. The peak at $1710 \mathrm{~cm}^{-1}$ confirms the presence of carboxylic acid, and another peak at $1740 \mathrm{~cm}^{-1}$ indicates the ester group on the surface of all TAADFPs along with raw adsorbent. A strong peak at $1200 \mathrm{~cm}^{-1}$ is due to the $\mathrm{C}-\mathrm{O}$ stretch of ester which gives further evidence of the ester group on the surface. Weak peaks at $1369-1237.40 \mathrm{~cm}^{-1}$ indicated $-\mathrm{C}-\mathrm{H}$ bending vibrations, and $826.16-531.43 \mathrm{~cm}^{-1}$ indicates the presence of $\mathrm{C}-\mathrm{Cl}$ stretching of alkyl halides [34, 35]. Some of the peaks present in the IR spectrum of raw adsorbent are missing in the IR spectra of TAADFPs, and some peaks shifted, and the shapes of some peaks changed, indicating that the functional groups present on the adsorbent changed during the activation process. The FT-IR spectra of TAADFPs activated at different temperatures of 450, 500, 550 , and $600^{\circ} \mathrm{C}$ showed no significant difference. This is because the temperature range is small, and hence, the rate of evaporation (dehydration) and devolatilization is almost the same.

3.2. Optimization of Parameters. To get optimal conditions for optimum adsorption, the response surface methodology (RSM) with Design-Expert software suggested 21 experiments with different sets of operational parameters (Table 1). The regression equation derived from the analysis of variance (ANOVA) shows that $R^{2}$ is between 0.7957 and 0.9950 , the multiple correlation coefficients. It should be noted that the model's suitability is indicated by an $R^{2}$ value greater than 0.75 . Results from ANOVA verified that the quadratic model was satisfactorily adapted to the experimental results.

3.3. Defluoridation Process. To optimize the conditions for optimum adsorption performance, twenty-one experiments were performed with different sets of parameters obtained from response surface methodology (RSM). At $600^{\circ} \mathrm{C}$, TAADFP demonstrated the highest efficacy of adsorption (98.36 percent) at $\mathrm{pH} 2$, initial concentration of $27.5 \mathrm{mg} / \mathrm{L}$, contact time of 75 minutes, and adsorbent dose of $5.5 \mathrm{~g}$, respectively (Table 1 ). Increasing the activation temperature increases the efficiency of adsorption from 450 to $600^{\circ} \mathrm{C}$. This is due to the rise in the number of pores, increased surface 


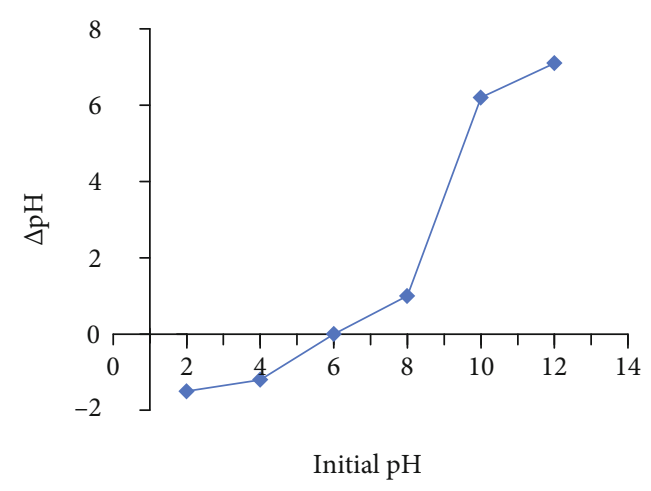

(a)

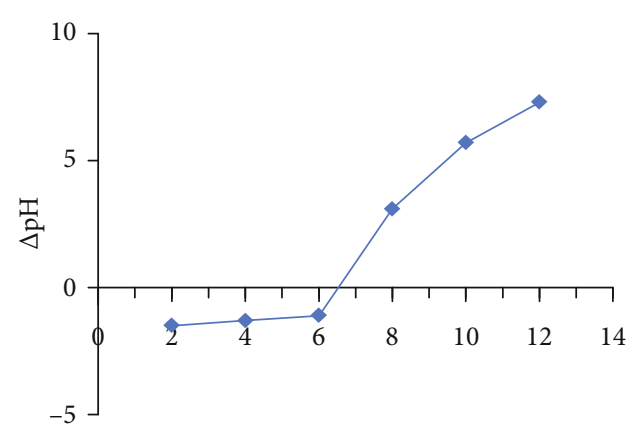

Initial $\mathrm{pH}$

(c)

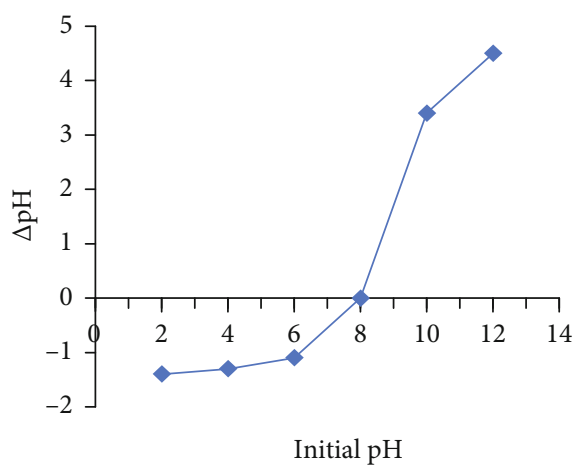

(b)

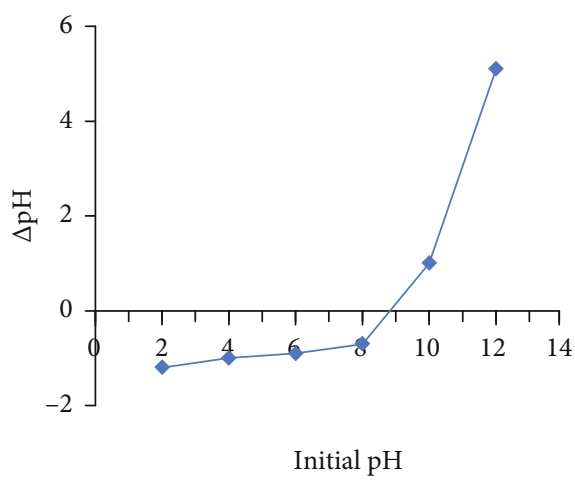

(d)

Figure 2: $\mathrm{pH}$ at point of zero charge for TAADFPs activated at (a) $450^{\circ} \mathrm{C}$, (b) $500^{\circ} \mathrm{C}$, (c) $550^{\circ} \mathrm{C}$, and (d) $600^{\circ} \mathrm{C}$.

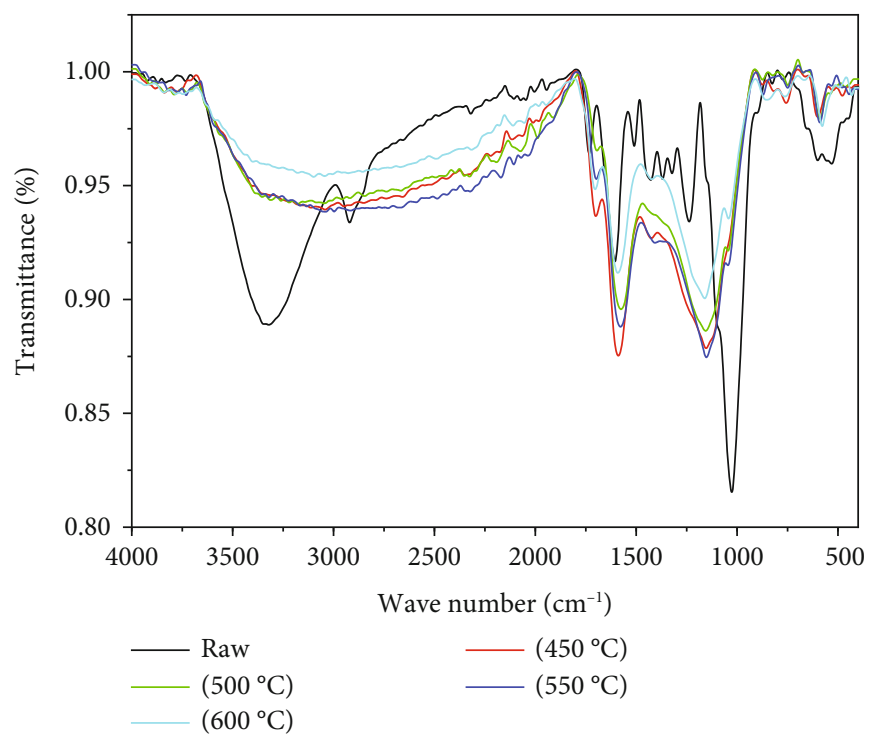

FIgURE 3: The FT-IR spectra for raw and TAADFPs activated at different temperatures.

area, channels, and exposure of acidic functional groups that have occurred during thermal activation resulting from dehydration and devolatilization. Also, with a decrease in $\mathrm{pH}$ and an increase in the dose of adsorbent, the amount of $\mathrm{F}^{-}$adsorbed increased. The $\mathrm{pH}$ value of the aqueous solution is an important controlling parameter in the adsorption process. The low $\mathrm{pH}$ value affected the surface charge of the adsorbents, the degree of ionization, and the speciation of adsorbate that favored $\mathrm{F}^{-}$ion adsorption. A decrease in $\mathrm{pH}$ results in an increase in positive charges that accelerate the adsorption of $\mathrm{F}^{-}$ions. The decrease in $\mathrm{pH}$ results in an increase in the positive charges that significantly improve $\mathrm{F}^{-}$ion adsorption. The increase in the adsorbent dose increases the potency of 
TABle 1: Different experiments suggested by Design-Expert software for the optimization of conditions of $\mathrm{pH}$, initial concentration (IC), contact time (CT), and adsorbent dose (AD) for defluoridation using TAADFPs.

\begin{tabular}{lcccccccc}
\hline & & & & \multicolumn{5}{c}{ Adsorption efficiency (\%) for } \\
Run & $\mathrm{pH}$ & $\mathrm{IC}$ & $\mathrm{CT}$ & $\mathrm{AD}$ & \multicolumn{3}{c}{ TAADFPs activated at } \\
& & $(\mathrm{mg} / \mathrm{L})$ & $(\mathrm{min})$ & $(\mathrm{g})$ & \multicolumn{2}{c}{ different temperatures } \\
& & & & & $450^{\circ} \mathrm{C}$ & $500^{\circ} \mathrm{C}$ & $550^{\circ} \mathrm{C}$ & $600^{\circ} \mathrm{C}$ \\
\hline 1 & 12.00 & 5.00 & 30.00 & 10.00 & 57.12 & 78.72 & 70.55 & 72.73 \\
2 & 2.00 & 50.00 & 120.00 & 10.00 & 91.72 & 93.97 & 89.70 & 93.17 \\
3 & 7.00 & 27.50 & 75.00 & 5.50 & 92.99 & 94.47 & 84.43 & 89.16 \\
4 & 3.00 & 50.00 & 25.00 & 5.50 & 71.24 & 78.79 & 70.37 & 78.80 \\
5 & 6.00 & 5.00 & 30.00 & 1.00 & 68.63 & 67.68 & 79.19 & 91.94 \\
6 & 4.00 & 27.50 & 75.00 & 5.50 & 92.37 & 93.15 & 91.27 & 91.57 \\
7 & 2.00 & 27.50 & 75.00 & 5.50 & 67.61 & 92.57 & 90.52 & 98.36 \\
8 & 5.00 & 5.00 & 120.00 & 10.00 & 63.85 & 91.22 & 91.70 & 89.60 \\
9 & 10.00 & 50.00 & 120.00 & 1.00 & 68.26 & 78.71 & 53.85 & 58.91 \\
10 & 5.00 & 27.50 & 30.00 & 5.50 & 92.68 & 93.96 & 77.42 & 96.36 \\
11 & 8.00 & 27.50 & 30.00 & 5.50 & 91.01 & 93.70 & 77.39 & 88.70 \\
12 & 4.00 & 27.50 & 25.00 & 5.50 & 88.91 & 93.17 & 86.22 & 87.16 \\
13 & 6.00 & 50.00 & 25.00 & 1.00 & 79.35 & 78.48 & 71.95 & 76.94 \\
14 & 3.00 & 27.50 & 120.00 & 10.00 & 95.55 & 96.50 & 96.88 & 94.67 \\
15 & 6.00 & 27.50 & 75.00 & 5.50 & 94.29 & 56.62 & 91.94 & 93.44 \\
16 & 2.00 & 50.00 & 30.00 & 10.00 & 88.41 & 91.92 & 80.05 & 64.94 \\
17 & 12.00 & 5.00 & 30.00 & 5.50 & 53.98 & 50.94 & 75.45 & 59.49 \\
18 & 10.00 & 27.50 & 75.00 & 5.50 & 87.46 & 93.15 & 85.05 & 93.15 \\
19 & 6.00 & 27.50 & 75.00 & 1.00 & 46.34 & 75.87 & 63.85 & 71.99 \\
20 & 4.00 & 27.50 & 120.00 & 5.50 & 93.26 & 93.17 & 97.65 & 94.67 \\
21 & 8.00 & 5.00 & 120.00 & 1.00 & 63.02 & 75.92 & 62.96 & 71.54 \\
\hline & & & & & & & &
\end{tabular}

the active sites and thereby increases the efficacy of adsorption. At a lower adsorbent dose, adsorption efficiency increases rapidly and then decreases slightly as it increases to the optimum dose. It is, however, of interest to note that any increase in the adsorbent dose above the maximum value results in a reduction in the efficacy of adsorption. This is because the adsorbent dose increases the development of intraparticle interactions such as aggregation, resulting in a decrease in the total surface area of the adsorbent, an increase in the length of the diffusion path, and thus a decrease in the density of adsorption [20]. The $\mathrm{pH}$ and adsorbent dose pattern demonstrated by all TAADFPs is consistent with the findings of previous studies [3]. Adsorption efficiency and capacity increased with the increase in contact time for all the adsorbents up to 75 minutes above which they started to decline. This is because, after this time, the available active sites and pores were occupied and saturated with adsorbates. When the $\mathrm{pH}$ is high, contact time seems to have little effect, suggesting that the biosorbent adsorption mechanism is controlled by $\mathrm{pH}$. The interaction between the functional groups and $\mathrm{F}^{-}$is a function of the $\mathrm{pH}$ of the medium to which the adsorbent is subjected. Defluoridation usually increases with a $\mathrm{pH}$ decrease, similar to previous studies [9].

\subsection{Mutual Effects of Parameters on Adsorption Efficiency of Fluoride}

3.4.1. Effect of $p H$ and Contact Time. Figure 4 shows that contact time did not affect the adsorption process at high $\mathrm{pH}$, but at low $\mathrm{pH}$, fluoride adsorption efficiency improved as contact time increased. In an acidic medium, the surface of the adsorbent is highly protonated due to which it is positively charged, and hence, more fluoride ions can be attracted toward the surface. The presence of positive charges on the surface of the adsorbent creates a Coulombic force of attraction between a positively charged adsorbent's surface and negatively charged fluoride. For all adsorbents, the adsorption efficiency decreased with an increase in $\mathrm{pH}$. This is due to the deprotonation of the adsorbent surface. Thus, the $\mathrm{pH}$ of 2 gave maximum fluoride removal (98.36 percent). This is due to the generation of positively charged surfaces of the adsorbent at low $\mathrm{pH}$. The surface of the adsorbent is strongly protonated in the acidic medium, and more fluoride ions can therefore be drawn to the surface. At low $\mathrm{pH}$, they also exhibited high adsorption efficiency (2 to 6). At different pHs, various adsorbents showed distinct adsorption efficiencies. TAADFP activated at $450^{\circ} \mathrm{C}$ has the highest adsorption performance of $95.55 \%$ at $\mathrm{pH} 3$, TAADFP activated at $500^{\circ} \mathrm{C}$ is $95.50 \%$ at $\mathrm{pH} 3$, TAADFP activated at $550^{\circ} \mathrm{C}$ is $97.65 \%$ at $\mathrm{pH} 4$, and TAADFP activated at $600^{\circ} \mathrm{C}$ is $98.36 \%$ at $\mathrm{pH} 2$ (Table 1).

The percentage of fluoride removal decreased with rising $\mathrm{pH}$ for all adsorbents. This is due to a rise in $\mathrm{OH}^{-}$ concentration, which competed for adsorption with $\mathrm{F}^{-}$. The surfaces of the adsorbents were negatively charged above $\mathrm{pH}_{\mathrm{pzc}}(\mathrm{pH}=6)$, retarding the diffusion of fluoride ions. The reduction in adsorption above $\mathrm{pH}_{\mathrm{pzc}}$ is due to the repulsive interaction between the anionic fluoride and the surface of the adsorbent that is negatively charged. Similar findings were recorded elsewhere for fluoride ion adsorption on other biosorbents [11].

In this study, the contact time ranged from 30 to 120 minutes. Initially, adsorption increased from 30 and 75 minutes between two phases, that is, adsorbent and solution containing adsorbate ions (Figure 4). When it reaches the optimal value, maximum adsorption occurs due to the attainment of an equilibrium state. After this, there is no considerable increase or decrease in adsorption by increasing contact time. Hence, a further increase in contact time did not enhance the biosorption in all the prepared adsorbents; therefore, the optimum contact time was 75 minutes. This may be justified by the fact that initially, all the binding sites were vacant and available for sorption, and adsorbate ions became easily bounded to these sites; moreover, the solute concentration gradient was high [36]. As time passes, more and more adsorbate ions get attached to these active sites. Afterward, the uptake of fluoride ions decreased due to a decrease in the number of available adsorption sites. When reaching the optimal time value, all the available adsorbent sites become saturated or occupied, and after this, a continuous process of adsorption and desorption starts, due to which no further increase or decrease in adsorption occurs [37]. 


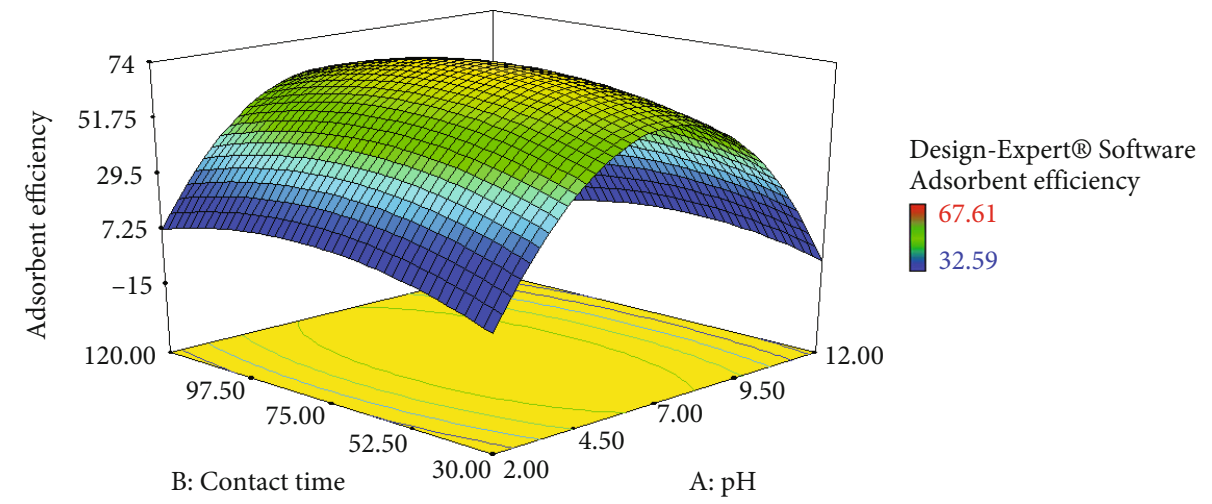

(a)

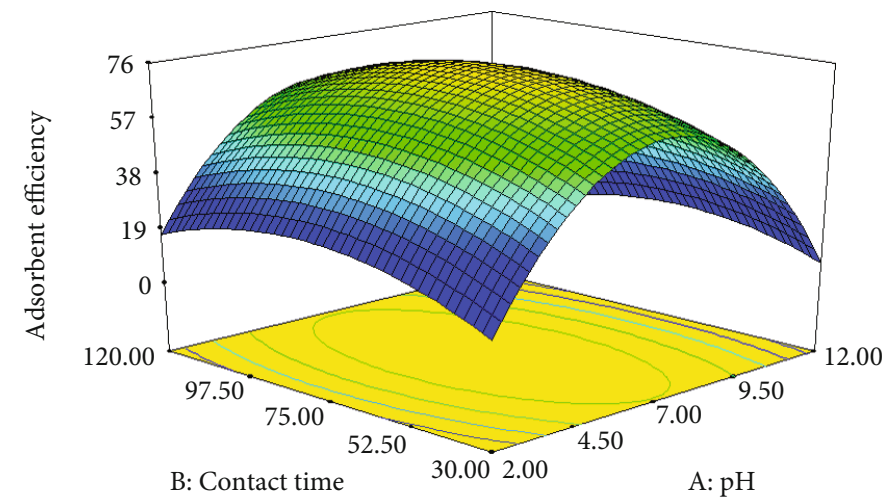

Design-Expert ${ }^{\circledR}$ Software Adsorbent efficiency

91.91

32.59

(b)

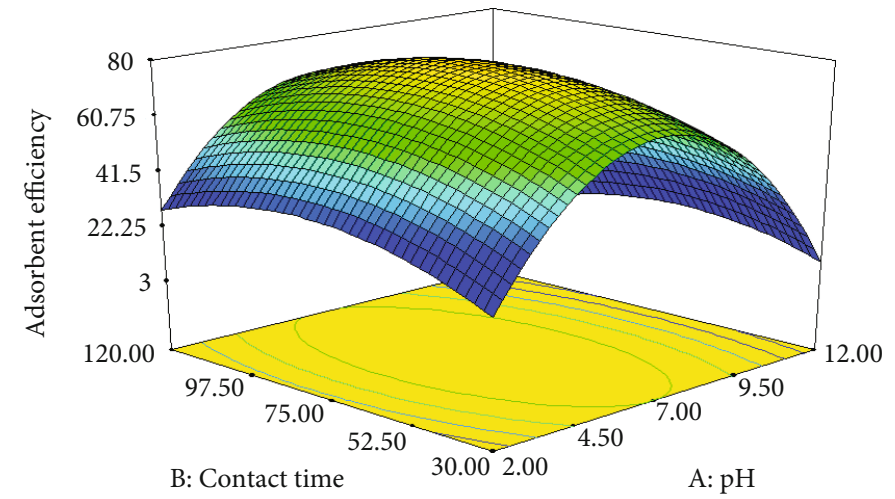

Design-Expert@ Software Adsorbent efficiency

96.5

32.59

(c)

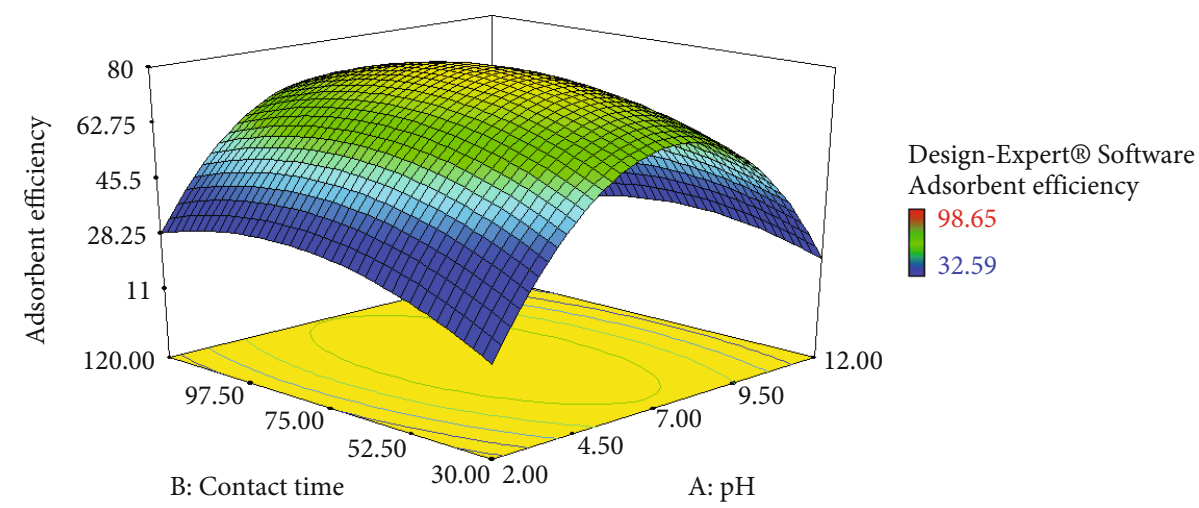

(d)

Figure 4: Mutual effect of $\mathrm{pH}$ and contact time on the adsorption efficiency of TAADFPs activated at (a) $450^{\circ} \mathrm{C}$, (b) $500^{\circ} \mathrm{C}$, (c) $550^{\circ} \mathrm{C}$, and (d) $600^{\circ} \mathrm{C}$. 


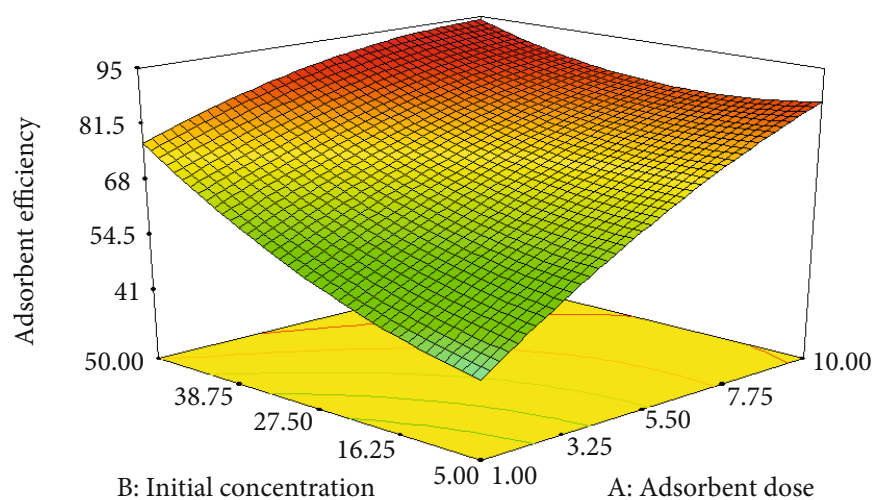

(a)

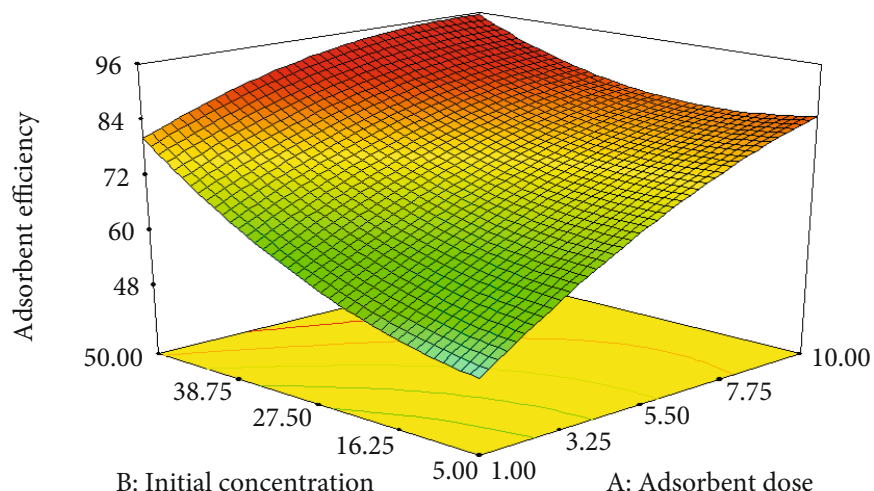

(b)

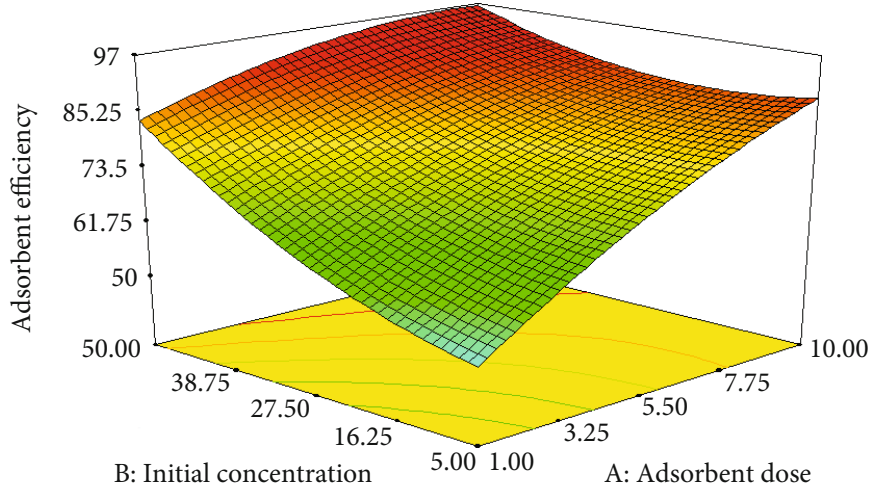

(c)

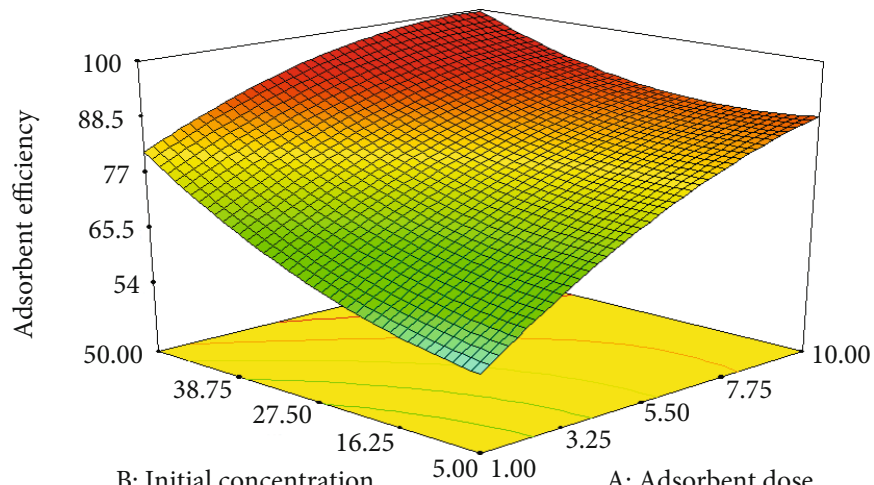

(d)

FIGURE 5: Mutual effect of adsorbent dose and initial concentration on the adsorption efficiency of TAADFPs activated at (a) $450^{\circ} \mathrm{C}$, (b) $500^{\circ} \mathrm{C}$, (c) $550^{\circ} \mathrm{C}$, and (d) $600^{\circ} \mathrm{C}$. 


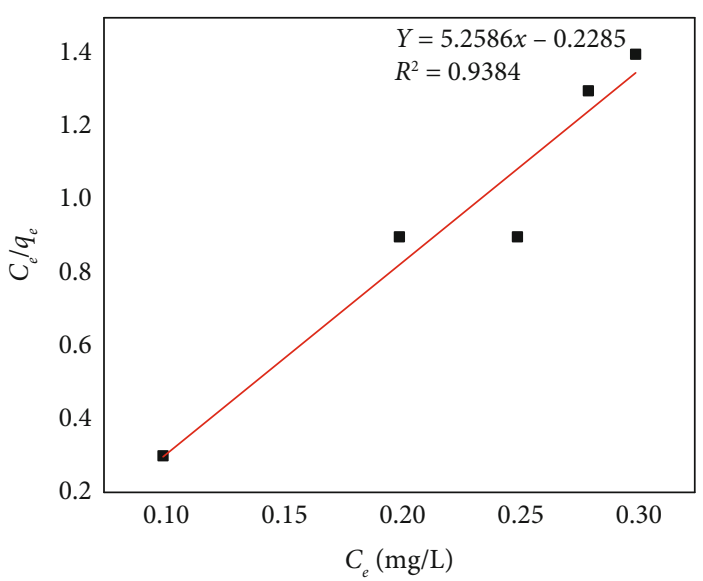

(a)

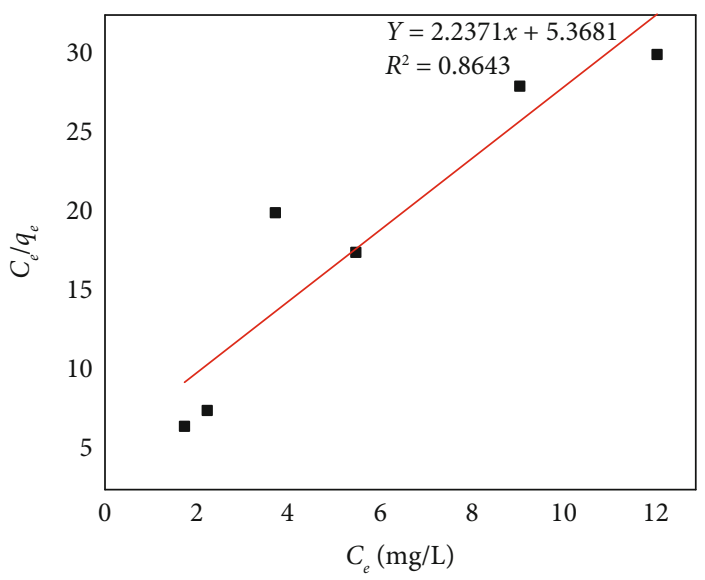

(c)

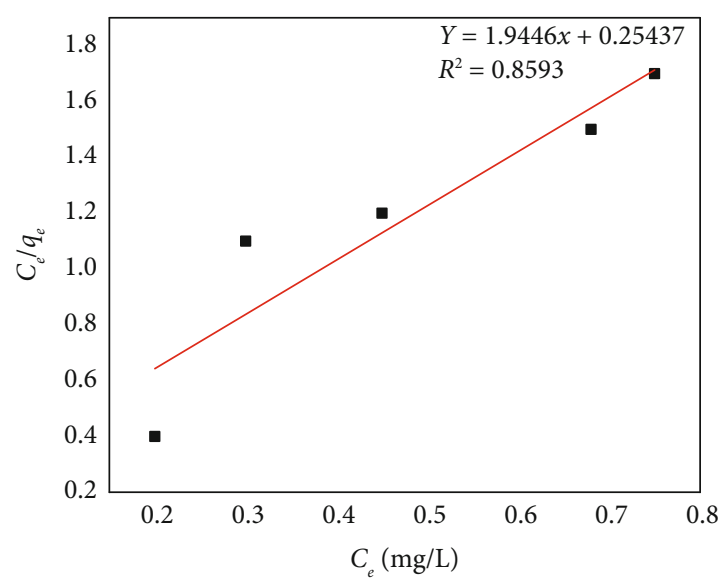

(b)

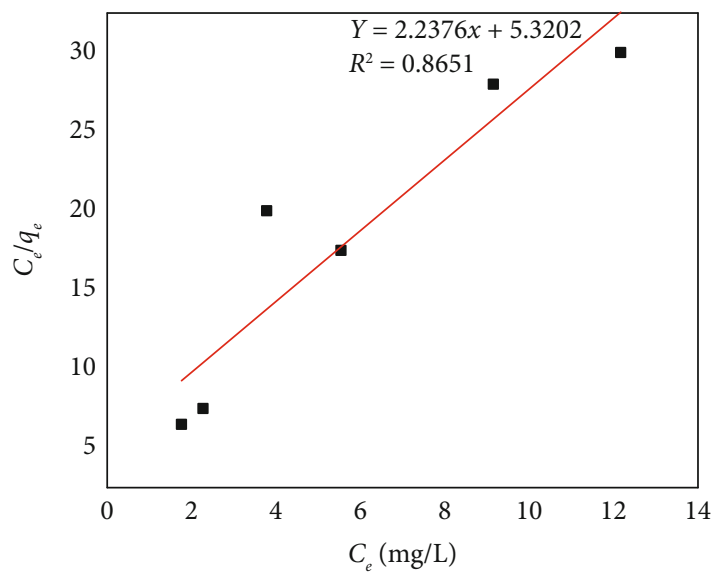

(d)

Figure 6: Langmuir adsorption isotherms for fluoride adsorption by TAADFPs activated at (a) $450^{\circ} \mathrm{C}$, (b) $500^{\circ} \mathrm{C}$, (c) $550^{\circ} \mathrm{C}$, and (d) $600^{\circ} \mathrm{C}$.

3.4.2. Effect of Adsorbent Dose and Initial Concentration. The entire adsorption process is a function of the initial concentration of the pollutant ions, which makes it an important factor to be determined for effective sorption. The effect of initial concentration was investigated from 5 to $50 \mathrm{mg} / \mathrm{L}$. The removal efficiency of adsorbents increased with increasing initial fluoride concentrations (Figure 5). This is due to the higher concentration gradient. Removal efficiency increases up to a concentration of $27.5 \mathrm{mg} / \mathrm{L}$ and then decreases as concentration rises. The decrease in removal efficiency with increasing fluoride is because there are not enough available active sites on the adsorbent surface in comparison with the large number of active sites which are required for a high concentration of fluoride. This concurs with several previous studies [37].

The adsorption efficiency increased with an increase in the adsorbent dose (Figure 5). This is due to a large number of available $\mathrm{F}^{-}$binding sites resulting from the increased adsorbent dose. The increase in load capacity is due to the availability of a higher number of fluoride ions per unit mass of adsorbent, i.e., a higher fluoride/adsorbent ratio [26]. Thus, the defluoridation efficiency (\%) significantly increased with dose as can be reflected by the results in Table 1. The removal rate at the beginning of the adsorption process was observed to be faster, which is consistent with several other studies [26]. This is probably due to the large available surface area of the adsorbent.

3.5. Adsorption Isotherms. There was a consideration of adsorption isotherm studies to describe the nature of the biosorbent surface and the affinity of the adsorbent at a fixed operating condition. Both Langmuir and Freundlich adsorption isotherm models were studied.

3.5.1. Langmuir Isotherms. Langmuir isotherm is based on the assumption that a point of valance exists on the surface of the adsorbent and that each of these sites is capable of adsorbing one molecule. It is assumed that the adsorption sites have equal affinities for molecules of adsorbate and that the presence of adsorbed molecules at one site will not affect the adsorption of molecules at an adjacent site [3]. The Langmuir isotherm assumes monolayer adsorption onto a surface containing a finite number of adsorption sites of uniform strategies of adsorption with no transmigration of adsorbate in the plane of the surface. The Langmuir adsorption 


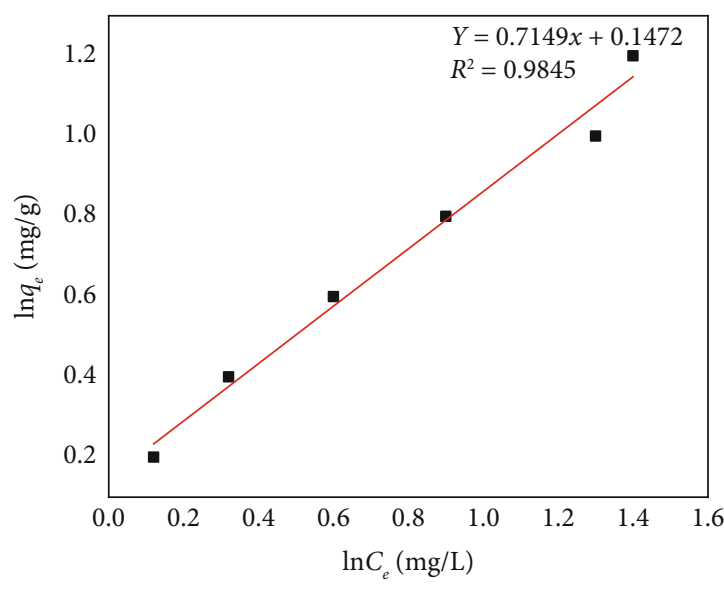

(a)

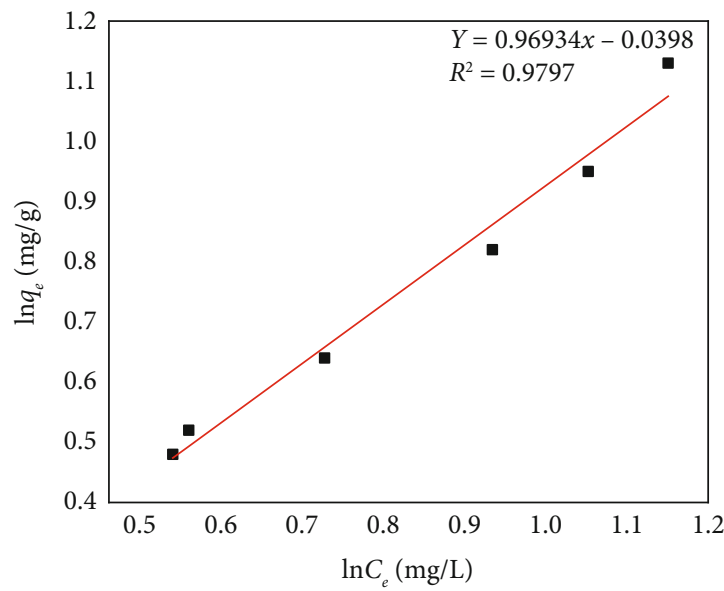

(c)

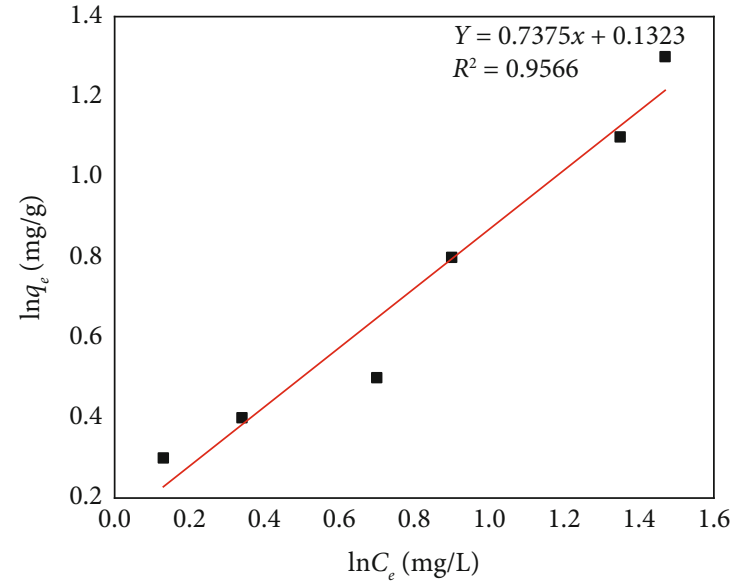

(b)

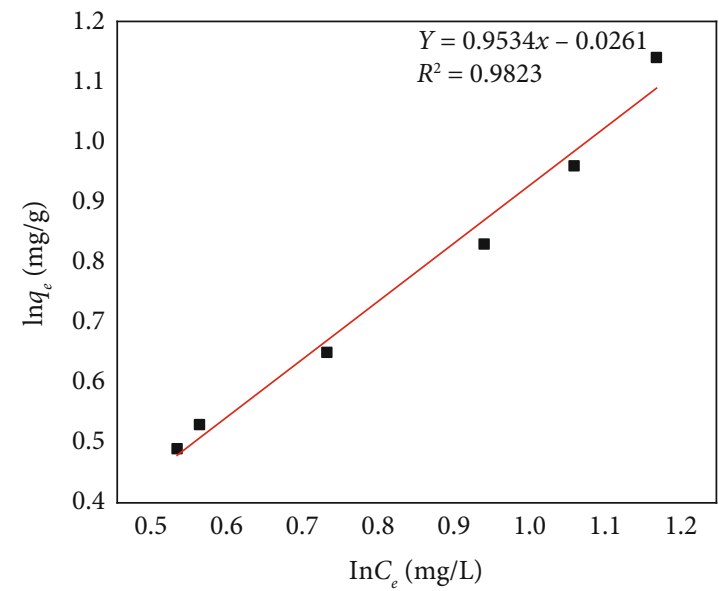

(d)

Figure 7: Freundlich adsorption isotherms for fluoride adsorption by (a) TAADFP at $450^{\circ} \mathrm{C}$, (b) TAADFP at $500^{\circ} \mathrm{C}$, (c) TAADFP at $550^{\circ} \mathrm{C}$, and (d) TAADFP at $600^{\circ} \mathrm{C}$.

isotherm equation in a linearized form is represented in

$$
\frac{C_{e}}{q_{e}}=\frac{C_{e}}{q_{o}}+\frac{1}{k_{L} q_{o}},
$$

where $q_{e}$ is the amount of fluoride adsorbed per unit weight of adsorbent $(\mathrm{mg} / \mathrm{g})$ at equilibrium, $C_{e}$ is the equilibrium concentration $\left(\mathrm{mg} \mathrm{L}^{-1}\right)$, and $q_{o}$ and $k_{L}\left(\mathrm{dm}^{3} \mathrm{~g}^{-1}\right)$ are the Langmuir constants, related to the adsorption capacity and energy of adsorption, respectively.

A plot of $C_{e} / q_{e}$ versus $C_{e}$ gives a straight line with intercept $1 / k_{L} q_{o}$ and slope $1 / q_{o}$. According to Figure 6, the Langmuir isotherm did not have a good fit for the adsorption process but indicated favorable adsorption having $R^{2}$ close to one for all the TAADFPs.

3.5.2. Freundlich Isotherms. The isotherm of Freundlich was interpreted as sorption to heterogeneous surfaces or surfaces that support varied affinity sites. Freundlich isotherm assumes unlimited sorption sites which correlate better with the heterogeneous surface of the adsorbent media. It is also believed that it first occupied the stronger binding sites and that with increasing degree of site occupation the binding strength decreases. The energy of fluoride ion binding to a site on an adsorbent in this model depends on whether the neighboring sites are already occupied or not. The expression for Freundlich adsorption isotherm is represented by the following linearized equation:

$$
\ln q_{e}=\ln k_{f}+\frac{1}{n} \ln C_{e},
$$

where $k_{f}$ is the Freundlich constant that relates to sorption capacity and $n$ is the Freundlich exponent that relates to sorption intensity.

The plot of $\ln q_{e}$ versus $\ln C_{e}$ gives a linear graph (Figure 7). From the graph, $n$ and $k_{f}$ were determined. The linear plots of $\ln q_{e}$ versus $\ln C_{e}$ for all the TAADFPs showed that the experimental data is better fitted to the Freundlich isotherm model with correlation coefficient $\left(R^{2}\right)$ values of $0.95661-0.98445$ close to 1 . The values of $n$ (1.0251-1.3989) that lie between 1 and 10 indicate a favorable adsorption process. According to the results of 


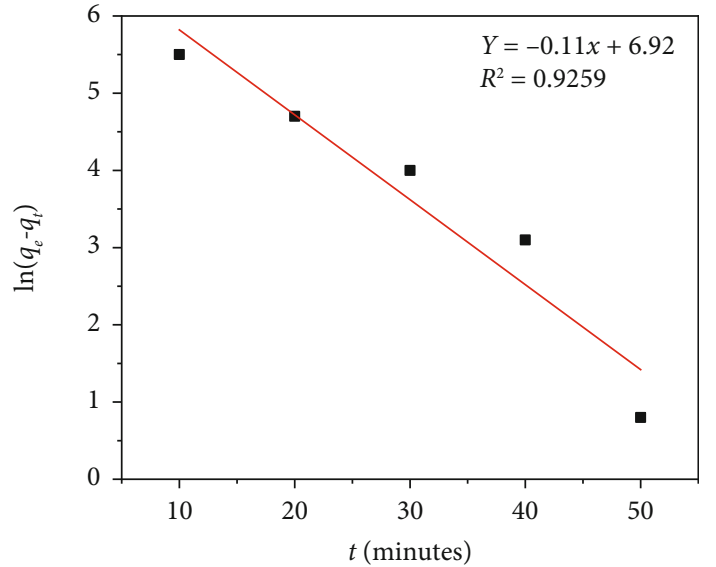

(a)

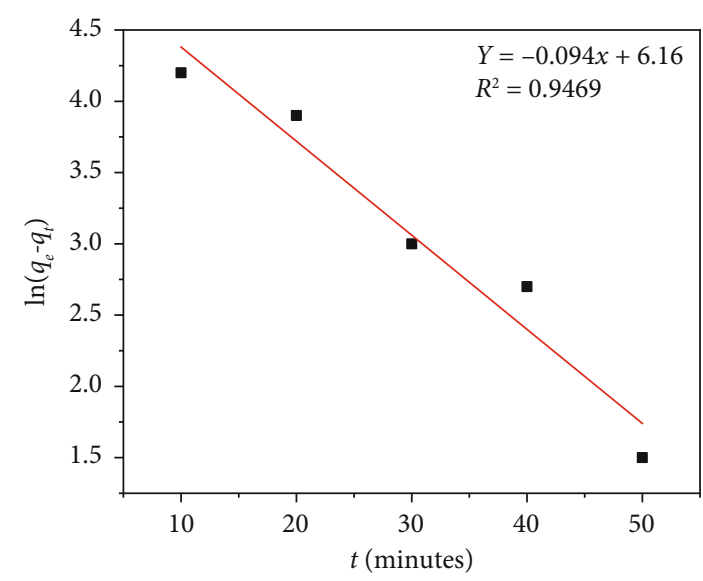

(c)

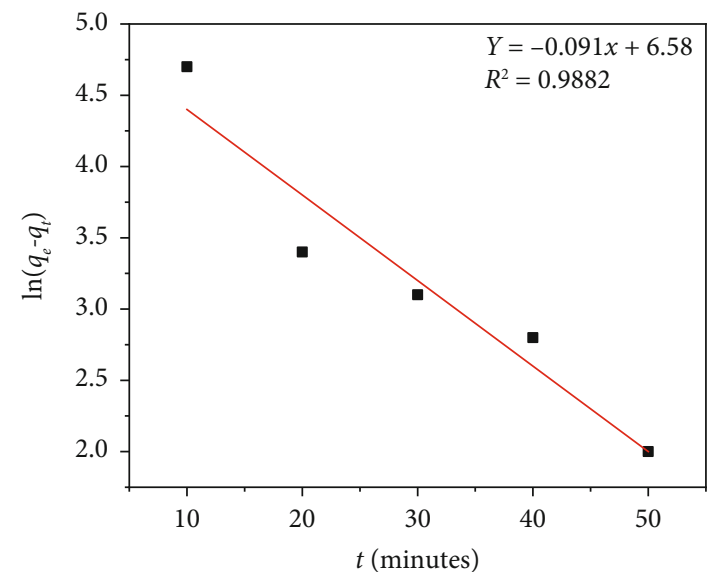

(b)

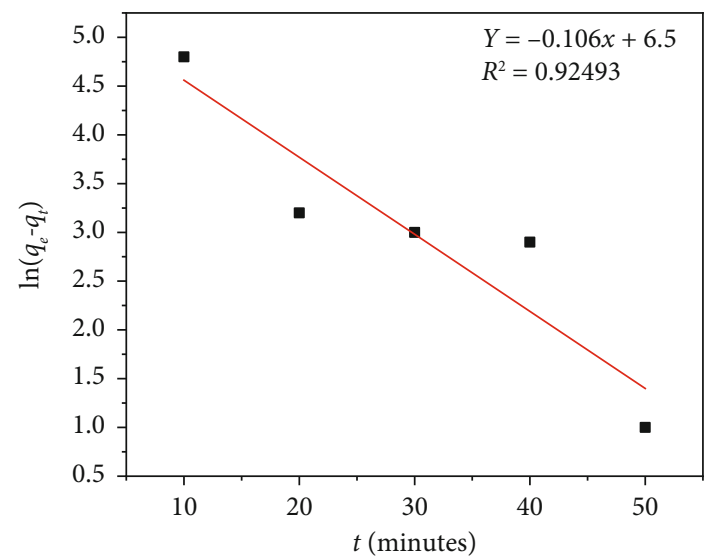

(d)

Figure 8: Pseudo-first-order plots for fluoride adsorption by the adsorbents (a) TAADFP at $450^{\circ} \mathrm{C}$, (b) TAADFP at $500^{\circ} \mathrm{C}$, (c) TAADFP at $550^{\circ} \mathrm{C}$, and (d) TAADFP at $600^{\circ} \mathrm{C}$.

this study, the correlation coefficient of the Freundlich model was higher than that of the Langmuir model, indicating that the Freundlich model is suitable for describing the adsorption equilibrium of $\mathrm{F}^{-}$onto the adsorbents. A similar result was reported by Lavecchia and coworkers on fluoride removal from aqueous solutions by a high alumina content bauxite [1].

The adsorption capacities $q_{o}$ of TAADFPs activated at $450,500,550$, and $600^{\circ} \mathrm{C}$ are $0.1900,0.5143,0.4469$, and $0.4470 \mathrm{mg} / \mathrm{g}$, respectively. These values indicate that as activation temperature increased, the adsorption capacity increased. The adsorption intensities $n$ were 1.3989, 1.3560, 1.0316 , and 1.0491, with values ranging from 1 to 10 , indicating a favorable adsorption process [20]. The higher fluoride removal capacity at equilibrium indicates the heterogeneous nature of the adsorbent surface which is characteristic of adsorption following the Freundlich adsorption isotherm model.

3.6. Kinetics of Fluoride Adsorption. To illustrate the mechanism of fluoride adsorption, kinetic experiments have been performed. To research the adsorption process, pseudo-firstand pseudo-second-order kinetics have been used.
3.6.1. Pseudo-First-Order Kinetics. The pseudo-first-order model is described by the linear equation:

$$
\ln \left(q_{e}-q_{t}\right)=\ln q_{e}-k_{1} t
$$

where $q_{t}$ is the fluoride concentration adsorbed on adsorbent at any time (mg of fluoride/g of adsorbent), $q_{e}$ is the amount of fluoride adsorbed per unit weight of adsorbent $(\mathrm{mg} / \mathrm{g})$ at equilibrium, and $k_{1}$ is the adsorption rate constant $\left(\mathrm{min}^{-1}\right)$. The pseudo-first-order plots of $\ln \left(q_{e}-q_{t}\right)$ against $t$ for the adsorption of fluoride by TAADFPs are presented in Figure 8 . The correlation coefficient $R^{2}$ can be obtained from the graph.

3.6.2. Pseudo-Second-Order. The pseudo-second-order model is described by the linear equation:

$$
\left(\frac{t}{q_{t}}\right)=\frac{1}{k_{2} q_{e}^{2}}+\frac{1}{q_{e}}(t)
$$

where $k_{2}$ is the adsorption rate constant ( $\left.\mathrm{g} / \mathrm{mg} \mathrm{min}\right)$. Pseudosecond-order kinetic data was used to draw pseudo-secondorder plots of $t / q_{t}$ against $t$, and they gave the linear graph 


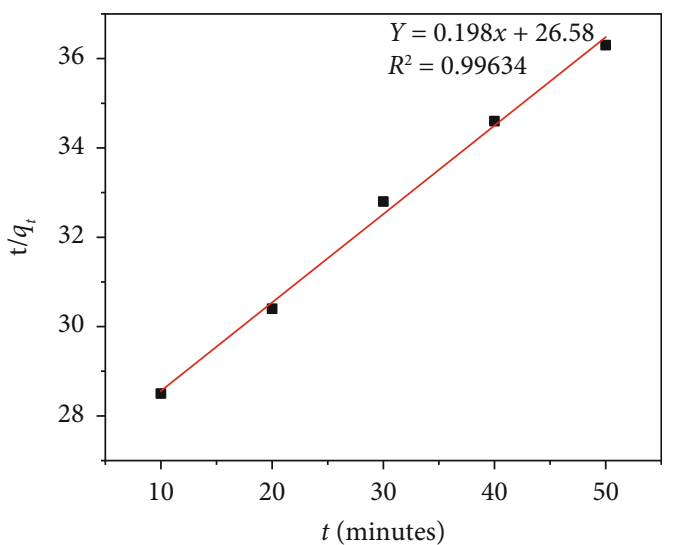

(a)

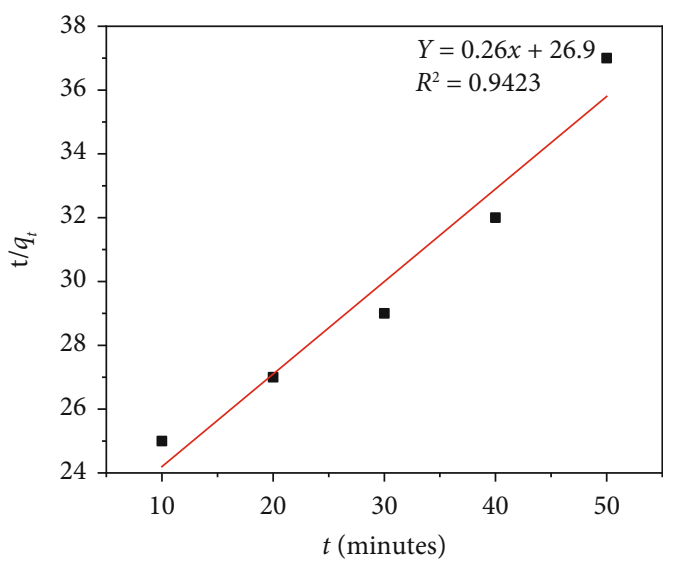

(c)

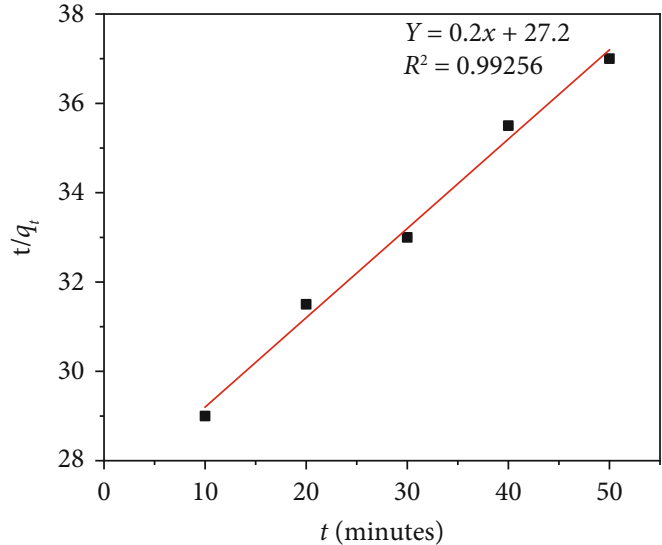

(b)

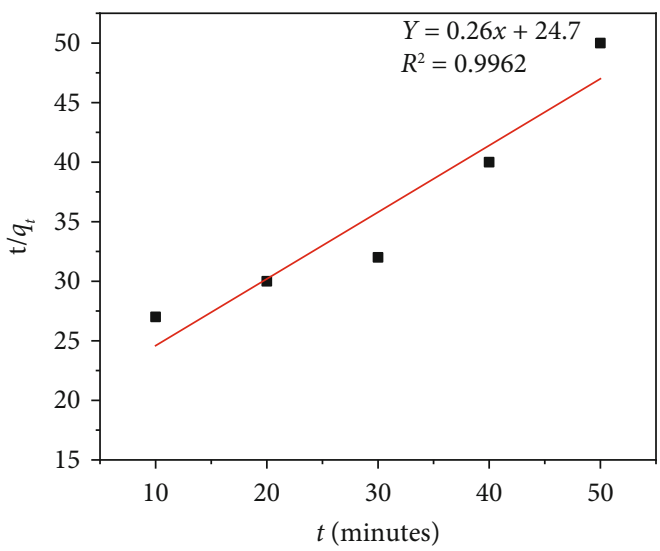

(d)

Figure 9: Pseudo-second-order plots for fluoride adsorption by the adsorbents (a) TAADFP at $450^{\circ} \mathrm{C}$, (b) TAADFP at $500^{\circ} \mathrm{C},(\mathrm{c}) \mathrm{TAADFP}$ at $550^{\circ} \mathrm{C}$, and (d) TAADFP at $600^{\circ} \mathrm{C}$.

TABLE 2: Desorption and resorption of fluoride by TAADFPs activated at $450,500,550$, and $600^{\circ} \mathrm{C}$ using distilled water and $0.1 \mathrm{M} \mathrm{NaCl}$ (pH 5 , initial fluoride concentration $5 \mathrm{mg} / \mathrm{L}$, contact time 1 hour at room temperature).

\begin{tabular}{lccccccccc}
\hline $\begin{array}{l}\text { TAADFPs } \\
\text { activated at }\left({ }^{\circ} \mathrm{C}\right)\end{array}$ & $\begin{array}{c}\mathrm{F}^{-} \text {resorbed } \\
(\mathrm{mg} / \mathrm{L})\end{array}$ & $\begin{array}{c}\mathrm{F}^{-} \text {desorbed } \\
(\mathrm{mg} / \mathrm{L})\end{array}$ & $\begin{array}{c}\text { Percent } \\
\text { removal }(\%)\end{array}$ & $\begin{array}{c}\mathrm{F}^{-} \text {resorbed } \\
(\mathrm{mg} / \mathrm{L})\end{array}$ & $\begin{array}{c}\text { Second cycle } \\
\mathrm{F}^{-} \text {desorbed } \\
(\mathrm{mg} / \mathrm{L})\end{array}$ & $\begin{array}{c}\text { Percent } \\
\text { removal }(\%)\end{array}$ & $\begin{array}{c}\mathrm{F}^{-} \text {resorbed } \\
(\mathrm{mg} / \mathrm{L})\end{array}$ & $\begin{array}{c}\text { Third cycle } \\
\mathrm{F}^{-} \text {desorbed } \\
(\mathrm{mg} / \mathrm{L})\end{array}$ & $\begin{array}{c}\text { Percent } \\
\text { removal }(\%)\end{array}$ \\
\hline 450 & 4.31 & 3.92 & 86 & 4.25 & 3.80 & 85 & 3.52 & 3.10 \\
500 & 4.34 & 3.94 & 87 & 4.32 & 3.55 & 86 & 4.14 & 3.45 \\
550 & 4.46 & 4.21 & 89 & 4.39 & 3.85 & 88 & 4.25 & 3.64 & 85 \\
600 & 4.58 & 4.32 & 92 & 4.35 & 4.13 & 87 & 4.26 & 3.95 \\
\hline
\end{tabular}

(Figure 9). The correlation coefficient $R^{2}$ can be obtained from the graph.

The mean value of the correlation coefficient $R^{2}$ for all the TAADFPs for the pseudo-second-order model (0.97266) is greater than that of the pseudo-first-order model (0.85634). As it can be seen from Figure 9, the data fitted well with the second-order kinetic model $\left(R^{2}>0.97\right)$. Similar kinetic results have been reported by Mapfaire and coworkers in the defluoridation of water by rice husk ash silicahydroxyapatite adsorbent [26]. Therefore, the best-fit model for all adsorbents (TAADFPs) is the pseudo-second-order model. This implies that all stages of adsorption such as external film diffusion, diffusion, and internal particle diffusion took place. This model assumes that the adsorption process involves a chemisorption mechanism including sharing or transferring electrons between the adsorbent and adsorbate. It takes place in heterogeneous conditions because it depends on the amount of solute adsorbed at a time, $t$, and considers adsorption to be the rate-controlling step.

3.7. Desorption, Regeneration, and Reuse. Desorption experiments were conducted to evaluate the reusability of the spent adsorbents. According to Table 2, the removal efficiency reached as high as $86,87,89$, and $92 \%$ for TAADFPs 
activated at $450,500,550$, and $600^{\circ} \mathrm{C}$, respectively, and started to diminish as the process was repeated (Table 2). These results indicated that SMADFP and TAADFPs could be repeatedly used in the biosorption process by regenerating using the distilled water- $\mathrm{NaCl}$ medium. Table 2 shows the ability of regenerated adsorbent for defluoridation as the number of cycles versus percentage removal. There is only a marginal loss of adsorption capacity, and substantial amounts of fluoride can be removed. It is noted that the percentage of removal has not fallen below $70 \%$ even in the third cycle. Hence, the spent active biosorbents were found to regain their lost sorption nature after treatment, in distilled water- $\mathrm{NaCl}$ conditions, to a great extent.

\section{Conclusions}

The adsorbents exhibited good physical and chemical characteristics to act as biosorbents as depicted by SEM, BET, and IR analysis. The maximum removal efficiencies of TAADFPs activated at $450,500,550$, and $600^{\circ} \mathrm{C}$ were 95.55 , $96.50,97.65$, and $98.36 \%$, respectively, which means that the adsorbents were effective for the removal of fluoride. All the TAADFPs researched in the present study followed the Freundlich isotherm model and second-order kinetics for the removal of fluoride. The TAADFPs examined in this study showed promising properties as a low-cost and effective adsorbent for the removal of fluoride from water.

\section{Data Availability}

All the data used to support the findings of this study is included within the article.

\section{Conflicts of Interest}

The authors declare that there is no conflict of interest with respect to the research, authorship, and/or publication of this article.

\section{References}

[1] R. Lavecchia, F. Medici, L. Piga, G. Rinaldi, and A. Zuorro, "Fluoride removal from water by adsorption on a high alumina content bauxite," Chemical Engineering Transactions, vol. 26, pp. 295-300, 2012.

[2] N. Chen, Z. Zhang, C. Feng, N. Sugiura, M. Li, and R. Chen, "Fluoride removal from water by granular ceramic adsorption," Journal of Colloid and Interface Science, vol. 348, no. 2, pp. 579-584, 2010.

[3] T. Getachew, A. Hussen, and V. M. Rao, "Defluoridation of water by activated carbon prepared from banana (Musa paradisiaca) peel and coffee (Coffea arabica) husk," International journal of Environmental Science and Technology, vol. 12, no. 6, pp. 1857-1866, 2015.

[4] M. Habuda-Stanic, M. E. Ravancic, and A. Flanagan, "A review on adsorption of fluoride from aqueous solution," Materials, vol. 7, no. 9, pp. 6317-6366, 2014.

[5] M. E. Kaseva, "Optimization of regenerated bone char for fluoride removal in drinking water: a case study in Tanzania," Journal of Water and Health, vol. 4, no. 1, pp. 139-147, 2006.
[6] S. Ayoob and A. K. Gupta, "Fluoride in drinking water: a review on the status and stress effects," Critical Reviews in Environmental Science and Technology, vol. 36, no. 6, pp. 433-487, 2006.

[7] B. Thole, W. R. L. Masamba, and F. W. Mtalo, "Water defluoridation by bauxite-gypsum magnesite (B-G-Mc) based filters calcined at 350 500C," International Journal of Physical Sciences, vol. 8, no. 19, pp. 956-962, 2013.

[8] S. V. Jadhav, E. Bringas, G. D. Yadav, V. K. Rathod, I. Ortiz, and K. V. Marathe, "Arsenic and fluoride contaminated groundwaters: a review of current technologies for contaminants removal," Journal of Environmental Management, vol. 162, pp. 306-325, 2015.

[9] M. Suneetha, B. S. Sundar, and K. Ravindhranath, "Removal of fluoride from polluted waters using active carbon derived from barks of Vitex negundo plant," Journal of Analytical Science and Technology, vol. 6, no. 1, pp. 1-19, 2015.

[10] D. A. Sahbaz, S. Dandil, and C. Acikgoz, "Removal of crystal violet dye by a novel adsorbent derived from waste active sludge used in wastewater treatment," Water Quality Research Journal, vol. 54, no. 4, pp. 299-308, 2019.

[11] S. Waghmare, T. Arfin, S. Rayalu, D. Lataye, S. Dubey, and S. Tiwari, "Adsorption behavior of modified zeolite as novel adsorbents for fluoride removal from drinking water: surface phenomena, kinetics and thermodynamics studies," International Journal of Science, Engineering and Technology Research, vol. 4, no. 12, pp. 4114-4124, 2015.

[12] WHO and UNICEF, Progress on drinking water and sanitation, , pp. 6-74, 2014, http://www.who.int/about/licensing/ copyright_form/en/index.html.

[13] A. W. Verla, M. Horsfall, E. N. Verla, A. I. Spiff, and O. A. Ekpete, "Preparation and characterization of activated carbon from fluted pumpkin (Telfairia Occidentalis Hook. F) seed shell," Asian Journal of Natural and Applied Sciences, vol. 1, no. 3, pp. 39-50, 2012.

[14] P. J. Rangari and P. Chavan, "A review on preparation of activated carbon from coconut shell," International Journal of Innovative Research in Science, Engineering and Technology, vol. 6, no. 4, pp. 5829-5849, 2017.

[15] R. H. Gumus and I. Okpeku, "Production of activated carbon and characterization from snail shell waste (\&lt;i\&gt;Helix\&lt;/i\&gt; \&lt;i\&gt;pomatia\&lt;/i\&gt;)," Advances in Chemical Engineering and Science, vol. 5, no. 1, pp. 5161, 2015.

[16] D. Das, D. P. Samal, and B. C. Melkap, "Preparation of activated carbon from green coconut shell and its characterization," Journal of Chemical Engineering \& Process Technology, vol. 6, no. 5, pp. 1-7, 2015.

[17] S. Mopoung, P. Moonsri, W. Palas, and S. Khumpai, "Characterization and properties of activated carbon prepared from tamarind seeds by $\mathrm{KOH}$ activation for $\mathrm{Fe}(\mathrm{III})$ adsorption from aqueous solution," The Scientific World Journal, vol. 2015, Article ID 415961, 9 pages, 2015.

[18] B. A. Fil, C. Ozmetin, and M. Korkmaz, "Cationic dye (methylene blue) removal from aqueous solution by montmorillonite," Bulletin of the Korean Chemical Society, vol. 33, no. 10, pp. 3184-3190, 2012.

[19] C. A. Nunes and M. C. Guerreiro, "Estimation of surface area and pore volume of activated carbons by methylene blue and iodine numbers," Quimica Nova, vol. 34, no. 3, pp. 472-476, 2011. 
[20] A. H. B. A. Bakar, Y. S. Koay, Y. C. Ching et al., "Removal of fluoride using quaternized palm kernel shell as adsorbents: equilibrium isotherms and kinetics studies," BioResources, vol. 11, no. 2, pp. 4485-4511, 2016.

[21] P. Zhu, H. Wang, B. Sun, P. Deng, S. Hou, and Y. Yu, “Adsorption of fluoride from aqueous solution by magnesia-amended silicon dioxide granules," Journal of Chemical Technology and Biotechnology, vol. 84, no. 10, pp. 1449-1455, 2009.

[22] I. A. W. Tan, A. L. Ahmad, and B. H. Hameed, "Preparation of activated carbon from coconut husk: optimization study on removal of 2,4,6-trichlorophenol using response surface methodology," Journal of Hazardous Materials, vol. 153, no. 1-2, pp. 709-717, 2008.

[23] A. Adewuyi and F. V. Pereira, "Nitrilotriacetic acid functionalized Adansonia digitata biosorbent: preparation, characterization and sorption of $\mathrm{Pb}$ (II) and $\mathrm{Cu}$ (II) pollutants from aqueous solution," Journal of Advanced Research, vol. 7, no. 6, pp. 947-959, 2016.

[24] R. Khandanlou, M. B. Ahmad, H. R. F. Masoumi, K. Shameli, M. Basri, and K. Kalantari, "Rapid adsorption of copper(II) and lead(II) by rice straw/ $\mathrm{Fe}_{3} \mathrm{O}_{4}$ nanocomposite: optimization, equilibrium isotherms, and adsorption kinetics study," PLoS One, vol. 10, no. 3, pp. 1-19, 2015.

[25] S. Srinu Naik and Y. Pydi Setty, "Optimization of parameters using response surface methodology and genetic algorithm for biological denitrification of wastewater," International journal of Environmental Science and Technology, vol. 11, no. 3, pp. 823-830, 2014.

[26] M. M. E. Mapfaire, C. Machingauta, and N. Muchanyereyi, "Preparation of rice husk ash silica-hydroxyapatite adsorbent for defluoridation of water: kinetic and equilibrium studies," International Journal of ChemTech Research, vol. 9, no. 9, pp. 75-84, 2016.

[27] X. Fan, D. J. Parker, and M. D. Smith, "Adsorption kinetics of fluoride on low cost materials," Water Research, vol. 37, no. 20, pp. 4929-4937, 2003.

[28] Z. G. Zhang, S. G. Cao, Y. Li, P. Guo, H. Yang, and T. Yang, "Effect of moisture content on methane adsorption and desorption-induced deformation of tectonically deformed coal," Adsorption Science \& Technology, vol. 36, no. 9-10, pp. 1648-1668, 2018.

[29] B. Veena Devi, A. A. Jahagirdar, and M. N. Zulfiqar Ahmed, "Adsorption of chromium on activated carbon prepared from coconut shell," International Journal of Engineering Research and Applications, vol. 2, no. 5, pp. 364-370, 2012.

[30] I. Ali, M. Asim, and T. A. Khan, "Low cost adsorbents for the removal of organic pollutants from wastewater," Journal of Environmental Management, vol. 113, pp. 170-183, 2012.

[31] M. A. Ahmad and N. K. Rahman, "Equilibrium, kinetics and thermodynamic of remazol brilliant orange $3 \mathrm{R}$ dye adsorption on coffee husk-based activated carbon," Chemical Engineering Journal, vol. 170, no. 1, pp. 154-161, 2011.

[32] B. Bestani, N. Benderdouche, B. Benstaali, M. Belhakem, and A. Addou, "Methylene blue and iodine adsorption onto an activated desert plant," Bioresource Technology, vol. 99, no. 17, pp. 8441-8444, 2008.

[33] Q. Hu, N. Chen, C. Feng, and W. W. Hu, "Nitrate adsorption from aqueous solution using granular chitosan- $\mathrm{Fe}^{3+}$ complex," Applied Surface Science, vol. 347, pp. 1-9, 2015.
[34] D. L. Pavia, G. M. Lapman, G. S. Kriz, and J. R. Vyvyan, Introduction to Spectroscopy, Brooks/Cole, Cengage Learning, Belmont, USA, 4th edition, 2009.

[35] R. M. Silverstein, F. X. Webster, and D. J. Kiemle, Spectrometric identification of organic compounds, John Wiley \& Sons, Hoboken, NJ, USA, 7th edition, 2005.

[36] T. Shalna and A. Yogamoorthi, "Preparation and characterization of activated carbon from used tea dust in comparison with commercial activated carbon," International Journal of Recent Scientific Research, vol. 6, no. 2, pp. 2750-2755, 2015.

[37] A. M. Echavarria-Alvarez and A. Hormaza-Anaguano, "Flower wastes as a low-cost adsorbent for the removal of acid blue 9," Dyna, vol. 81, no. 185, pp. 132-137, 2014. 